\title{
African Easterly Jet: Structure and Maintenance
}

\author{
Man-Li C. Wu* \\ Global Modeling and Assimilation Office \\ NASA Goddard Space Flight Center \\ Greenbelt, Maryland 20771 \\ Oreste Reale $^{\dagger}$ \\ Laboratory for Atmospheres \\ NASA Goddard Space Flight Center \\ Greenbelt, Maryland 20771 \\ Siegfried D. Schubert \\ Max J. Suarez \\ Randy D. Koster \\ Philip J. Pegion $\ddagger$ \\ Global Modeling and Assimilation Office \\ NASA Goddard Space Flight Center \\ Greenbelt, Maryland 20771
}

May 20, 2009

\footnotetext{
*Email Man-Li.C.Wu@nasa.gov

${ }^{\dagger}$ Additional Affiliation: University of Maryland, Baltimore County, Baltimore, Maryland

‡Current Affiliation: National Ocean and Atmosphere Administration, Camps Springs, Maryland
} 


\begin{abstract}
This article investigates the African Easterly Jet (AEJ), its structure and the forcings contributing to its maintenance, critically revisiting previous work which attributed the maintenance of the jet to soil moisture gradients over tropical Africa.

A state-of-the-art global model in a high-end computer framework is used to produce a 3-member 73-year ensemble run forced by observed SST to represent the Control run. The AEJ as produced by the Control is compared with the representation of the AEJ in the European Center for Medium Range Forecast Reanalyses (ERA-40) and other observational data sets and found very realistic.

Five Experiments are then performed, each represented by sets of 3-member 22 year long (1980-2001) ensemble runs. The goal of the Experiments is to investigate the role of meridional soil moisture gradients, different land surface properties and orography. Unlike previous studies, which have suppressed soil moisture gradients within a highly idealized framework (i.e., the so-called bucket model), terrestrial evaporation control is here achieved with a highly sophisticated landsurface treatment and with an extensively tested and complex methodology. The results show that the AEJ is suppressed by a combination of absence of meridional evaporation gradients over Africa and constant vegetation, even if the individual forcings taken separately do not lead to the AEJ disappearance, but only its modification. Moreover, the suppression of orography also leads to a different circulation in which there is no AEJ. This work suggests that it is not just soil moisture gradients, but a unique combination of geographical features present only in northern tropical Africa, which causes and maintains the jet.
\end{abstract}




\section{Introduction}

The African Easterly Jet (AEJ) is one of the most complex and intriguing dynamical features in tropical meteorology. It raises a number of questions, ranging from its formation mechanism to its maintenance, and from the causes of its intensity fluctuations to its role in generating weather systems. The AEJ is a crucial element in global-, synoptic- and meso-scale dynamics, and its representation in models is important for climate modeling, seasonal predictions, and weather forecasting.

This work uses a combination of state-of-the-art global reanalyses and model experiments, to shed light on some aspects of the AEJ. A general discussion of the problem and a literature review are presented in the next Section. Section 3 provides a description of the data and the NASA Seasonal-Interannual Prediction Project (NSIPP) Atmospheric General Circulation Model (AGCM), version 1 (NSIPP-1). Section 4 describes a set of five Experiments and a Control run that are carried out to investigate the role of soil moisture, vegetation and orography in maintaining and controlling the AEJ. In Section 5 the structure of the AEJ is analyzed as it appears in the reanalyses and in the Control run. This is followed by a discussion of all the forcings introduced in the Experiments and the resulting impact on the AEJ. Section 6 discusses the dynamical implications of the Experiments and Section 7 states the conclusions of this work. 


\section{The AEJ: previous research}

Besides the Inter Tropical Convergence Zone (ITCZ) the three planetary features that most prominently control the northern African summer and tropical Atlantic weather systems are the Saharan thermal low, the Tropical Easterly Jet (TEJ) and the AEJ (e.g. Asnani 2005). The Saharan thermal low can be considered as an extension of the planetary-scale thermal trough associated with the Asian monsoon. It affects the troposphere from the surface up to about $600 \mathrm{hPa}$ above which is replaced by relatively high geopotential values and divergence. It is the main feature controlling the so-called Harmattan flow, a low-level predominantly northeasterly flow sweeping over northwestern Sahara during summer and contributing to Saharan dust outbreaks into the Atlantic ocean. The TEJ, located at about 100$200 \mathrm{hPa}, 5^{\circ}$ to $15^{\circ} \mathrm{N}$, and stretching from Indo-China to the tropical Atlantic, has been shown to be linked to anomalous SSTs on a planetary scale (Chen and Loon 1987). It plays a paramount role in controlling the easterly vertical shear over developing weather systems off the Atlantic coast of Africa.

It appears, however, that of the above phenomena, the AEJ exerts the strongest influence on the occurrence, intensity, and frequency characteristics of the African weather systems within the west African Monsoon region (e.g. Cook 1999). That influence appears to extend well beyond the monsoon region to impact a substantial fraction of tropical Atlantic weather systems (e.g. Asnani 2005).

Hamilton and Archibald (1945) should be remembered among the first authors to present evidence of the AEJ. Based on a surface wind-based definition of the 
ITCZ (i.e. wind-veering line) they described Sahelian Africa to be characterized by four fundamental zones. Regardless of the fact that modern definitions of the ITCZ are based on the line where maximum vertical velocities occur rather than as the surface wind-veering line, the distinction of those four environments (A: north of the wind-changing line, characterized by dry Saharan air, B: between the $\mathrm{AEJ}$ and the wind-changing line, $\mathrm{C}$ : south of the AEJ, and D: far away to the south of the AEJ) and their different weather patterns, is still of enormous value and emphasizes the importance of the AEJ position. Moreover, these authors correctly ascertained the important role of the AEJ as a triggering mechanism of weather phenomena and the confinement of the weather systems to a very narrow band to the south of the AEJ.

In particular, the zone to the immediate south of the AEJ core, being subject to cyclonic shear and strong convective activity, has been recognized for decades as the area in which African Easterly Waves (AEWs) form, where several weather disturbances develop in form of squalls, and where the maximum precipitation is recorded. In particular, some authors have separated squall- by nonsquall- AEWs (e.g. Dhonneur 1971) and other authors have provided a much deeper understanding of squalls (e.g. Houze 1977; Zipser and Gautier 1978). To this day, one of the most comprehensive studies on AEWs is perhaps the 3-part work by Kiladis et al. (2006); Hall et al. (2006); and Thorncroft et al. (2008).

However, in this work AEWs are not treated and the focus is only on the AEJ structure and maintenance. Despite the importance of the AEJ as a prominent feature of African meteororology, the observational network over northern Africa has 
been deemed not adequate to completely capture its fine structure. Parker et al. (2008) state that "in recent years the meteorological observing system of Africa has been in a worse state than that of any other populated continent." In addition to the poor observing network, the diagnosis of the AEJ through global, relatively low-resolution datasets, has shown some degree of uncertainty. Differences in height, shape and intensity of the jet were noted by Cook (1999), while comparing the gridded climatologies of the National Centers for Environmental Predictions (NCEP) with the European Centre for Medium-Range Weather Forecasts (ECMWF). With respect to the AEJ, Cook (1999) notes that the AEJ maximum easterly velocities are $11 \mathrm{~m} \mathrm{~s}^{-1}$ at $500 \mathrm{hPa}$ in the ECMWF data, and $12.5 \mathrm{~m} \mathrm{~s}^{-1}$ at $600 \mathrm{hPa}$ in the NCEP reanalyses (Kistler et al. 2001), contrasting with a 8-year observational data set (Burpee 1972) that shows the AEJ max at about $650 \mathrm{hPa}$. Moreover, as observed by Cook in the same work, the shape of the AEJ differs too, being more displaced to the east in the NCEP data. These important differences were attributed by the author to sampling problems and relatively low resolution.

The relative scarcity of observations is also stressed in a more recent observational experiment, called Jet 2000 (Thorncroft et al. 2003), in which the jet height was found at about $675 \mathrm{hPa}$, and more to the south than expected, but possibly in agreement with the behavior of the AEJ in dry years. The Data Assimilation and forecasting Systems from ECMWF and the United Kingdom Met Office were initialized with some of the campaign data and provided reasonable representations in the AEJ although some differences between the two systems were noted (Thorncroft et al. 2003). 
Increasing vertical and horizontal resolution in more recent data sets have not yet totally dissipated some ambiguity in the AEJ definition, as it will be shown later. In addition to insufficient observational coverage and models' resolution, several important aspects may be at this point still inadequately represented. For example, Tompkins et al. (2005) show that the ECMWF 5-day forecast of the AEJ, which had a bias with respect to observations (being too far north, too weak and at a greater height than observed) was substantially improved by including a realistic, annually-varying, aerosol climatology. A different treatment of aerosols may be then at least partly responsible for the discrepancy.

Given that uncertainties in defining the strength, horizontal extent and height of the observed AEJ may be reduced in the future by a denser observational network, as advocated by the proponents of the African Monsoon Multidisciplinary Analysis (AMMA, described, among others, by Redelsperger et al. 2006), improved data assimilation capabilities and higher resolution, this will not directly address the more fundamental problems related to the AEJ, involving its physical causes, its maintenance and its ability to produce and confine the tracks of weather systems.

A relevant study that assesses the possible forcings on the maintenance of the AEJ is by Thorncroft and Blackburn (1999). In this work the authors compare the importance of the surface fluxes, low-level heating and dry convection associated with the Saharan thermal low, against the role of deep moist convection taking place in the ITCZ. Their conclusion is that it is the low-level heating, which extends vertically up to about $700 \mathrm{hPa}$, to play the most prominent role in 
maintaining the AEJ.

Accepting that the mean position of the AEJ may be controlled predominantly by low-level thermal forcing, the problem of interannual variability connected with intensity fluctuations or changes in position has been the subject of investigation for several decades. Amidst the considerable amount of literature available, perhaps two different but not necessarily antithetical views can be extracted: one that emphasizes the importance of global or Atlantic or Indian Ocean SSTs, and one that emphasizes the role of land-surface properties. In the former category, one can mention among many other studies the work by Foland et al. (1986); Semazzi et al. (1996); Nicholson (1997); Nicholson and Kim (1997), and Vizy and Cook (2001). In the latter category, studies stressing the importance of land surface properties start with the seminal works of Charney on the albedo impact in semi-arid regions (e.g. Charney et al. 1977) and more recently include the increasingly sophisticated description of land-surface characteristics, including vegetation properties, as potential modulators of north-African rainfall on a variety of time-scales (e.g., Xue and Shukla 1993; Zeng and Neelin 2000; Clark et al. 2004; Douville et al. 2005; Hagos and Cook 2005).

All these different perspectives are perceived as fundamentally concurring mechanisms in the study on Sahelian droughts by Giannini et al. (2003), where evidence is presented that Sahelian rainfall variability may be controlled by oceanic forcings and amplified by land-atmosphere interaction.

Of particular relevance for the present work is the study by Cook (1999), which showed with great clarity the importance of the AEJ in controlling west 
African precipitation, and quantified the connection between the Saharan thermal low and the steep soil moisture gradients observed from the wet areas close to the Guinea coast to the dry environment of the Saharan desert, as prominent mechanism controlling the AEJ. Hsieh and Cook (2005) expanded on these findings by showing the interdependence of the ITCZ and the AEJ in the generation of AEWs, Cook and Vizy (2006) analyze and review the capability of coupled GCMs to reproduce the overall west African Monsoon dynamics, and Hsieh and Cook (2007) investigate the energetics of AEWs within a regional framework. All these latter study, and many others, make assumptions based upon Cook (1999) and do not discuss the maintenance of the AEJ.

In the work presented here, which is focused on the AEJ and not on the AEWs, we follow Cook (1999) by looking in more detail, and with a less idealized model, at the impacts of surface conditions on the AEJ. Cook's study, for example, used zonally prescribed clouds, perpetual July conditions, a bucket model of the land surface, no topography and a uniform albedo of 0.1 . The conclusion that under these conditions the AEJ is produced by prescribing soil moisture alone does not address the importance of other factors or, indeed, the details of the soil moisture distribution or its relative impact in a more realistic setting. We thus decided to revisit the problem within a more realistic modeling framework and with a more rigorous set of experiments.

In this study, we start from a perspective opposite to Cook (1999): after examining the structure of the AEJ as represented in ERA-40, and in other reanalysis, we carry out a number of sensitivity experiments with a state-of-the-art global 
AGCM, with realistic topography and sophisticated land surface, that is capable of producing a realistic AEJ. In particular, a set of five experiments is performed: in four of them one forcing at a time is removed and in one two forcings are removed. By doing so, we separate the roles of soil moisture, orography and vegetation. The well-tested strategy developed by Koster and Suarez (1995, hereafter KS95), and Koster et al. (2000, hereafter KA00) is used to control land evaporation in AGCMs (see also Reale and Dirmeyer 2002; and Reale et al. 2002).

\section{Data and Model description}

The data used for this study are: a) the ERA-40 reanalyses (Uppala et al. 2005), a 6-hourly global data set covering more than 40 years, produced by the ECMWF, describing the state of the atmosphere from September 1957 to August 2002; b) the NCEP Department of Energy (NCEP-DOE) Reanalyses 2 (NCEP R2, Kistler et al. 2001; Kanamitsu et al. 2002) which cover about sixty years; and c) the Japanese 25-year Reanalyses (JRA-25, Onogi et al., 2007). In this work, only the subperiod between 1980 and 2001 is being used.

The model is the Global Modeling and Assimilation Office (GMAO) NSIPP$1 \mathrm{AGCM}$, run at a horizontal resolution of $2^{\circ} \times 2.5^{\circ}$ and with 34 vertical levels spaced to provide higher vertical resolution in the lower $2 \mathrm{kms}$ of the atmosphere. It is the same model that has been previously used by Wu et al. (2006) to investigate the seasonality and meridional propagation of the Madden Julian Oscillation (MJO). NSIPP-1 is a grid point model using a 4th-order dynamical core (Suarez and Takacs, 1995) with explicit leapfrog time differencing. The vertical coordi- 
nate is a standard sigma-coordinate and the vertical differencing follows Arakawa and Suarez (1983). The boundary layer scheme is a K-scheme calculating turbulent diffusivities for heat and momentum based on Monin-Obukhov similarity theory (Louis et al. 1982). Turbulent diffusivities are determined as function of roughness length, von Karman constant and a bulk boundary-layer Richardson number.

The relaxed Arakawa-Schubert (RAS) scheme is adopted to parameterize convection (Moorthi and Suarez 1992). RAS uses a sequence of simple linearlyentraining plumes (clouds types) that originate at the lowest sigma level and detrain at specific model levels. The initial clouds-base mass flux for each cloud type is determined from a convective available potential energy closure. The RAS scheme effectively acts as a parameterization of both deep and shallow convection in the NSIPP-1 model. Bacmeister and Suarez (2002) show that the model produces a reasonable simulation of the thermodynamic structure of the lower troposphere. The adopted parameterization of solar and infrared radiative heating is described in Chou and Suarez $(1994,1999)$. The solar heating includes absorption of $\mathrm{O}_{3}, \mathrm{CO}_{2}$, water vapor, $\mathrm{O}_{2}$, clouds, and gaseous and aerosol scattering.

The land surface model (LSM) is the Mosaic scheme of Koster and Suarez (1992, 1996), a soil-vegetation-atmosphere transfer LSM. The Mosaic scheme subdivides each AGCM grid square into subregions, called 'tiles', in which the vegetation type is relatively homogeneous, and then calculates separate one-dimensional energy and water balances over each tile, with strong stomatal control over transpiration rates. The LSM performance against observations has been discussed in 
Chen et al. (1997) and Wood et al. (1998).

The climate of the NSIPP-1 model and a more detailed model formulation are described in Bacmeister et al. (2000). Aspects of the model's climate variability are assessed by, among others, Pegion et al. (2000) and Schubert et al. (2002). This is the same model used in the investigation of Sahelian rainfall variability by Giannini et al. (2003) Of particular importance for this work is the model's ability to produce realistic AEJ and the good performance of the LSM documented in the studies above (see also Figs. 1 and 5 in this study), which makes it suitable for investigating the role of soil moisture in maintaining the AEJ.

\section{Experiments}

The Control runs consist of a three-member 73-year ensemble of simulations carried out at a horizontal resolution of $2^{\circ} \times 2.5^{\circ}$ and forced with observed monthly varying SSTs from 1930 to 2002 . The atmospheric initial conditions for the three members of the ensemble were arbitrarily chosen from previously completed simulations. Unlike earlier work (e.g. Thorncroft and Blackburn, 1999; Cook, 1999), which used highly idealized models, it should be stressed that this Control run is a relatively realistic climate simulation.

The purpose of the five Experiment runs is to examine the impacts of modified surface conditions in Equatorial and Saharan Africa obtained by 1) suppressing directly the meridional gradients of evaporation, 2) imposing meridionally uniform land surface properties (with two different settings), 3) simultaneously suppressing evaporation gradients and prescribing land surface properties, and 4) 
suppressing the orography's role. Each experiment consists of a three-member 27 -year ensemble of simulations (performed at the same resolution as that of the Control, with the same atmospheric initialization and the same observed monthly varying SSTs from 1978 to 2004), in which one of the forcings is disabled. The overall period (1978-2004) was chosen due to the much better quality of reanalyses available during the satellite era. The first two years of the each simulation are discarded for spin-up, and also the last three years are not included, in order to overlap with the ERA-40. All the statistics and subsequent analysis of this work are therefore based on the 22-year period 1980-2001.

One important aspect of our experiment settings is that the Control may be able to represent possible trends or fluctuations connected with changes in land surface properties. These have been documented over the region, and the actual Sahara-Sahel border has been shown to be subject to fluctuations (e.g. Tucker et al. 1991; Giannini et al. 2003).

The land interaction is disabled following the same conceptual design adopted by KS95 and KA00. The main goal is to disable the impact of evaporation variability, which is more difficult than disabling SSTs due to the intrinsic difference between SST's and soil moisture's control of evaporation. Following KS95 and KA00, the concept of "evaporability" or "evaporation efficiency" is therefore adopted. The evaporability $\beta$ is defined as the ratio between actual evaporation and potential evaporation. The former is given by

$$
E=\frac{\rho \epsilon}{p_{s}} \frac{e_{s}-e_{a}}{r_{a e r}+r_{\text {surf }}}
$$


where $\rho$ is the air density, $\epsilon$ is constant, $p_{s}$ is the surface pressure, $e_{s}$ is the saturated vapor pressure at the surface temperature, $e_{a}$ is the vapor pressure in the free air (namely, the lowest $\sigma$ level), $r_{a e r}$ is the aerodynamic resistance and $r_{s u r f}$ is the surface resistance, computed as a parallel resistance of all the resistances that contribute to it. Potential evaporation $E_{p}$ is calculated from actual evaporation when the surface resistance $r_{\text {surf }}$ is set to zero.

$$
E_{p}=\frac{\rho \epsilon}{p_{s}} \frac{e_{s}-e_{a}}{r_{a e r}}
$$

For each month and each year of the control run we compute the following ratio

$$
\beta_{m y}=\frac{\sum E(i)}{\sum E_{p}(i)}
$$

where the sums are over all the timesteps $i$ of that particular month and year. This allows the definition of a time series of $22 \times 12$ monthly $\beta$ s from the control run for each gridbox.

The climatological seasonal cycle of evaporability is obtained by averaging $\beta$ for each month throughout the 22-year period. Prescribing the evaporation efficiency in a simulation allows us to control continental evaporation in the simulations without directly prescribing the evaporation and yet disabling land-atmosphere feedbacks due to changes in surface water. As argued by KS95, this is a more general and direct way of accomplishing this than attempting to prescribe the water in all surface reservoirs. Once $\beta$ is prescribed, the actual evaporation for each time step is computed by multiplying $E_{p}(i)$ by the corresponding $\beta_{m}$.

In summary, the following experiments were performed: 
1. Experiment 1: the climatological set of $\beta_{m} \mathrm{~s}$ is averaged over the Sahel region (hereby defined as $10^{\circ}$ to $20^{\circ} \mathrm{N}$ and $20^{\circ} \mathrm{W}$ to $35^{\circ} \mathrm{E}$ ) and imposed on the rest of continental Africa. By doing so, evaporation interannual variability is suppressed and Sahelian conditions are prescribed.

2. Experiment 2: conditions of $\beta_{m}$ computed from Saharan values are imposed on the rest of Africa. This experiment acts in the opposite direction of Experiment 1. In fact, Experiment 1 imposes some evaporation over desert, thus reducing the meridional gradients of evaporation by increasing evaporation to the north of the gradient maximum, whereas Experiment 2 reduces evaporation over areas which are not desert, thus reducing the gradients by constraining evaporation to the south of the gradient maximum.

3. Experiment 3: the vegetation is imposed to be uniform, namely the predominant Sahelian land type (i.e., grassland) is imposed over the entire African continent, and the subgrid vegetation variability within each tile is suppressed. The primary effect is believed to be the suppression of albedo gradients and their effects on temperatures, but it also results in changes in surface roughness and hydrological properties associated with vegetated surfaces.

4. Experiment 4: the forcings of Experiment 1 and 3 are combined: vegetation and the evaporation efficiency are simultaneously prescribed to Sahel values.

5. Experiment 5: orography is imposed to be flat, eliminating any possible 
contributions induced by the southward sloping terrain over the Sahel, and by the Ethiopian highlands.

The Experiments' settings are summarized in Table 1.

\section{Analyses and experiment results}

Daily means were extracted from the five Experiments and the Control runs from the 1980-2001 period. In Fig 1, the zonal wind climatology for July, based on the ERA-40 data, the NCEP R2, and the JRA-25 are compared with the NSIPP-1 Control Run.

The fundamental properties of the AEJ and of the general circulation over northern Africa can be clearly distinguished in the 3 sets of reanalyses:

- a maximum of about $11 \mathrm{~ms}^{-1}$ at $600 \mathrm{hPa}$ approximately $15^{\circ} \mathrm{N}$ over western Africa

- a low-level westerly flow confined below $800 \mathrm{hPa}$ and affecting the latitude band between the Equator and $20^{\circ}$

- a low-level easterly flow (Harmattan) confined between $20^{\circ}$ and $30^{\circ} \mathrm{N}$

- an upper level easterly flow (TEJ) at latitudes south of $10^{\circ} \mathrm{N}$

- a shift in the AEJ position between May and July from about $9^{\circ} \mathrm{N}$ to $15^{\circ} \mathrm{N}$, followed by a $20 \%$ AEJ speed decline in October and southward symmetric displacement (not shown) 
Previous work by Cook (1999, Fig. 1) showed a remarkable difference in the AEJ maximum speed, of about $20 \%$, between the older European Center and NCEPNCAR reanalyses, and suggested resolution as a possible cause for the discrepancy. In the more recent datasets, ERA-40, NCEP R2 and JRA-25, wich are presented in this paper, the AEJ Maximum is at about the same value of approximately $11 \mathrm{~ms}^{-1}$. Also the location of the maximum, which Cook (1999) noted to differ substantially, tends to be in all analyses concentrated at about $10^{\circ}-15^{\circ}$ longitude $\mathrm{W}$.

However, the structure of the AEJ as represented in the two reanalyses still differs especially on its eastern side, with the ERA-40 representation of the AEJ consisting of a secondary speed maximum over the Aethopian highlands. The JRA-25, which is a more recent product, agrees more closely to the NCEP R2 as for the location of the jet maximum, but more to the ERA-40 as for the shape of the AEJ over central-eastern Africa. Quantitatively, speed differences of about $20 \%$ exist between JRA-25 and NCEP R2 at longitudes between $20^{\circ}$ and $40^{\circ} \mathrm{E}$.

The cross-section at $0^{\circ}$ longitude, extracted from the ERA-40, shows a welldefined AEJ core at about $600 \mathrm{hPa}$, well separated from the TEJ above $300 \mathrm{hPa}$ and from the low-level Harmattan flow centered between $27^{\circ}$ and $30^{\circ} \mathrm{N}$. Comparing this Figure with Fig. 2 in Cook (1999) and with NCEP R2 there is a good agreement on the low-level monsoonal flow between approximately $2^{\circ} \mathrm{N}$ and $20^{\circ} \mathrm{N}$ and the representation of the AEJ core at about $600 \mathrm{hPa}$. However, there is substantial difference in the representation of the Harmattan flow at about $27^{\circ} N$ : ERA-40 shows a much deeper Harmattan flow (up to $700 \mathrm{hPa}$ ) with a maximum located 
about $2^{o}$ in latitude further to the north with respect to the NCEP R2. Considering the importance of the Harmattan flow in advecting Saharan Air, and the implications of that for suppressing or limiting convection, the difference between the analysis seems significant. Another important difference is the intensity of the TEJ, which affects easterly vertical shear on the equatorward flank of the AEJ. The TEJ is almost $20 \%$ weaker in the ERA-40 data than in the NCEP R2. The JRA-25 is overall closer to the NCEP R2, except that the AEJ is definitely weaker on its eastern side in the JRA-25: at about $25^{\circ} E$ the difference is of the order of $40 \%$. Moreover, in the JRA-25 a separate speed maximum is evident on the Ethiopian highlands. This feature is also present in the ERA-40, but not in the NCEP R2. At this time, because of the relatively scarce observational network, these differences can only be acknowledged and it is not possible to make a final statement on which data set provides a more realistic representation. It should be emphasized however that even wind speed differences of small magnitude, relative to a feature as important as the AEJ, may be relevant considering that NCEP R2, ERA-40 and JRA-25 are state-of-the-art reanalysis products.

In Fig. 1 the July zonal wind mean computed from the NSIPP-1 three-member ensemble Control run is also shown. Given the uncertainties in the representation of the AEJ among different data sets, some degree of resemblance suggests that the NSIPP-1 is a reasonable simulation. The AEJ is clearly defined and well separated from the low-level Harmattan flow. Its maximum is at about $650 \mathrm{hPa}$, in agreement with the 8-year observation-based climatology (Burpee 1972), the ERA-40, NCEP R2 and JRA-25 data. The maximum is somewhat weaker, being 
about $7 \mathrm{~m} \mathrm{~s}^{-1}$, and it is also slightly displaced to the north. The relative weakness of the AEJ appears to be, in our model, a function of resolution. In experiments with the same model run at higher resolution $\left(1^{\circ} \times 1^{o}\right)$ the $\mathrm{AEJ}$ intensity is on the order of $9 \mathrm{~m} \mathrm{~s}^{-1}$ (not shown), close to the ERA-40 results. The shallow westerly monsoonal flow and the TEJ are also well defined. As for the AEJ life-cycle, the NSIPP simulation agrees well with the reanalyses with a northward shift of about $6^{0} N$ in the AEJ position occurring between May and July, and a symmetric southwad displacement, with decline in speed, in October (not shown). Moreover, being the positions of the AEJ, of the monsoonal flow and of the TEJ well represented at the peak of the monsoon, there is confidence that the NSIPP model is a valuable tool to investigate the forcings affecting the AEJ, even if the maximum speed of the AEJ as represented by the model is lower than the reanalyses. The purpose of this work is to gain a deeper understanding of the mechanisms controlling the basic AEJ structure and maintenance, and for this goal the NSIPP representation of the AEJ structure appears satisfactory.

To further investigate some properties of the AEJ, the structure of the AEJ with respect to the meridional horizontal shear of the zonal wind, is displayed in Figure 2. This quantity, corresponding to the relative vorticity produced by the zonal wind, is indicative of the part of the AEJ which may be more conducive to barotropic instability to develop. All the 3 data sets show a strip of positive values at about on the sourthern flank of the AEJ. The corresponding meridional cross-sections localize the heigths and latitudes which appear, according to these data sets, more likely to be barotropically unstable. All data sets agree that the 
strongest cyclonic shear induced by the AEJ is at about $600 \mathrm{hPa}$ and at about $10^{\circ} \mathrm{N}$, but the ERA-40 display a more confined maximum. The cross-sections also emphasize that in the ERA-40 the cyclonic shear appears to slope equatorward with height, which is the opposite of what is observed in the JRA-25.

To further investigate the problem of barotropic instability in the AEJ, we plot the quantity

$$
K(y)=\frac{\partial}{\partial y}\left[f(y)-\frac{\partial U}{\partial y}\right]
$$

where $f$ is the Coriolis parameter, and $U$ is the zonal wind. $K(Y)=0$ represents the well-known necessary condition for barotropic instability to occur in response to the zonal component of the flow. In our case, $K(y)=0$ on the cyclonic side of a flow indicates locations where barotropic instability is not impossible. This corresponds to $K(y)$ being zero to the north of positive values of $K$ and to the south of negative values of $K$ (when the flow is easterly). In Figure $3 K(y)$ is plotted against the zonal wind. The 3 data sets differ substantially on this regard. In particular the ECMWF builds a contiguous line with $\mathrm{K}=0$ on the southern flank of the AEJ, indicating that a strip of latitudes at about $10^{\circ} \mathrm{N}$ across the entire continent is potentially unstable for cyclonic disturbances to grow at the expenses of the mean flow. This contiguous feature is absent from the other data sets. Most remarkable is the presence, again in the ERA-40, of a contiguous vertical line of $K(y)=0$ sloping slightly poleward with increasing latitude and decreasing height, almost reaching the surface at about $12^{\circ} N$. A full investigation of the AEJ instabilities as AEWs-producing mechanisms should consider both baroclinic and barotropic instability as done by Hsieh and Cook (2008). This however would be 
beyond the purpose of this work, which is concerned on the AEJ structure and maintenance, and not on AEW production.

Figure 4 shows the mean vegetation and the orography used in the Control run. The vegetation follows a mosaic approach so that each gridbox is actually a mosaic of vegetation types with strong subgrid variability. The colors in Figures 4 identify the predominant vegetation type in each gridbox. The subgrid variability of land surface specifics cannot be easily represented in a map, but it should be emphasized that each grid box consists of up to six different kinds of land properties, including albedoes, roughness, vegetation cover, etc. The orography of the Control at this resolution is relatively smooth compared to reality, but the most important topographic features of the African continent are represented: namely the southern plateau, the Ethiopian highlands, the Atlas range, and the lower elevations of western Sahara. The effects on atmospheric dynamics resulting from the suppression of these features, as we will show later, are actually very strong.

Controlling the evaporation and modifying the vegetation distribution has powerful effects on the distribution of surface temperatures. Figure 5 shows the surface temperatures produced by the experiments, and the changes with respect to the Control. The uniform $\beta$ that uses Sahelian values everywhere cools the Sahara by more than $5^{\circ} \mathrm{C}$ and warms the area south of it by about $3-5^{\circ} \mathrm{C}$. When Saharan values of $\beta$ are imposed, the meridional temperature gradient changes in the opposite direction, with no change over the Sahara but a heating of up to $7-9^{\circ} C$ in the Sahel and to the south of it.

The uniform vegetation (Sahel type) imposed in the Experiment 3 leads to a 
cooling of the southern part of the Sahara and a warming in the northern part. The effect is opposite to Experiment 1, in which a constant $\beta$ is imposed.

The comparison of Experiment 1 (uniform $\beta$ ) and Experiment 3 (uniform vegetation) explains Experiment 4, in which both evaporation and vegetation properties are imposed to Sahelian values. In other words, the particular response of surface temperature to the changes in vegetation and evaporation is nonlinear and derives from the addition of two partly contrasting forcings.

Most interesting is the impact of the suppressed orography, which causes an increase of surface temperature comparable to the one in which uniform values of (Saharan) $\beta$ are imposed: namely a heating of $7-9^{\circ} C$, with maximum on the Ethiopian region. In addition to the temperature change induced by lower elevation, the increase is also connected with the reduction of topographic uplift which is in nature imposed on the monsoonal flow by the Ethopian highland, and that is being suppressed by the experiment. This causes a strong reduction in precipitation and latent heat flux. The heating is stronger where the reduction of precipitation is larger, and demonstrates the importance of the particular topography of northern Africa in controlling the monsoonal flow.

Figure 6 shows the JAS precipitation and the difference from the Control in all the experiments. The most striking result is that increasing $\beta$ over the Sahara (Experiment 1) does not produce large changes in precipitation while the opposite change, imposing Saharan $\beta$ everywhere, leads to a large reduction in precipitation over the Sahel. Another interesting and somewhat counterintuitive result is that prescribing uniform Sahelian type vegetation over Africa produces a much larger 
impact than prescribing Sahelian-type $\beta$, which leads to an impressive northward shift of the ITCZ (Experiment 3).

Experiment 4, in which both evaporation and vegetation are prescribed, clearly results in some nonlinear effects, in which the vegetation change (and presumably the albedo) dominates the evaporability change.

Of great interest is the result of the orography experiment (Experiment 5) which alone, without any modification to other surface forcings, can produce a dramatic reduction of precipitation throughout the Sahel region. The orographic effect, in fact, is comparable to the $\beta$ effect in Experiment 2, where Saharan values of evaporability are imposed. In other words, the removal of the topography of northern Africa can produce a reduction of precipitation almost equivalent to the one obtained by forcing the evaporability to be virtually zero.

Figure 7 displays the corresponding JAS surface latent heat fluxes in the various experiments, and their difference from the Control. Consistent with the above, Sahelian and Saharan values of $\beta$ alter the meridional gradients of latent heat (with Sahelian $\beta$ increasing latent heat over the Sahara and Saharan $\beta$ reducing latent heat south of the Sahara). Vegetation change and Sahelian $\beta$ change act in the same direction (increasing latent heat north of the Sahel, and decreasing it to the south), but the impact scale of $\beta$ is larger. This is reasonable because to prescribe $\beta$ over the desert leads to very strong evaporation with consequent large latent heat anomalies.

Figure 8 compares the meridional surface temperature gradients, a zonal crosssection of meridional temperature gradients at $12^{\circ} \mathrm{N}$ and the temperature structure 
in a meridional vertical cross section at $0^{\circ}$ longitude, in the Control and various Experiments. The displacement of precipitation induced by the Experiments corresponds well to the displacement of the strongest surface temperature gradients. The zonal cross-section of meridional gradients is computed from $180^{\circ} \mathrm{W}$ to $180^{\circ} \mathrm{E}$. However, changes with respect to the Control are noticeable, as expected, only over the longitudes corresponding to the African continent, where the surface conditions are altered in the experimental setup. Of particular significance is the suppression of the meridional thermal gradient inversion, on the top of the AEJ, between about $20^{\circ} \mathrm{W}$ and $60^{\circ} \mathrm{E}$, at about $600 \mathrm{hPa}$. In the Control, meridional temperature gradients are positive below $600 \mathrm{hPa}$, and vanish or become slightly negative at about $500 \mathrm{hPa}-600 \mathrm{hPa}$. In the uniform vegetation experiment (Experiment 3) and uniform vegetation and uniform $\beta$ experiment (Experiment 4) the meridional temperature gradients, albeit smaller with height, remain always positive. The meridional cross-sections of temperature at $0^{\circ}$ longitude further reinforce the notion that the thermal structure of the atmospheres is dramatically altered as a consequence of the Experiments, with evident changes in position and amplitude of the thermal maxima.

In Fig. 9 the zonal wind at $600 \mathrm{hPa}$, and a meridional vertical cross section at $0^{\circ}$ longitude are shown. The common feature between Experiments 1, 3 and 4 is the thickening and strengthening of the low-level westerly monsoonal flow at $0^{\circ}$ longitude. The Harmatthan flow is not suppressed in any experiment, since being simply driven by the always present summer thermal low over the Sahara.

In both Experiments 1 (with constant evaporability) and 3 (constant Sahelian 
vegetation), the AEJ is still present, albeit displaced and with different intensity (stronger and higher in Experiment 3, weaker and lower in Experiment 1).

It is in the Experiment 4, in which both vegetation and evaporation are simultaneously controlled, that the AEJ disappears. The relatively 'moderate' changes in the boundary forcings performed in Experiments 1 and 3 are not sufficient to suppress the AEJ, but only to change its intensity and position. The most drastic Experiment 2, which imposes Saharan-like conditions (through constant $\beta$ ) over all Africa does suppress the jet, but it is very important to note that a less extreme value of constant $\beta$ as the one obtained from grassland is not sufficient to destroy the jet. In other words, a 'moderate' control of evaporation (and thus soil moisture gradients) alone is not sufficient to suppress the AEJ, but is the combination of controlled evaporation and vegetation properties (inclusive of albedo) gradients together which suppresses the Jet. This finding partly contradict Cook's (1999) conclusions: in that study an AEJ was produced by the use of realistic soil moisture imposed over uniform albedo and the conclusion was made that only soil moisture is relevant. In this present work it is shown, by separating the various forcings, that the realistic vegetation types (inclusive of properties such as albedo) can also produce an AEJ even if evaporation is controlled. Since Cook $1999 \mathrm{did}$ not produce an experiment with realistic albedo and prescribed evaporation, it is suggested in this work that Cook's (1999) conclusions should be revisited.

Moreover, it is important to notice that the experiment in which orography is suppressed, but evaporation gradients and realistic vegetation are maintained, leads to a different circulation with a weaker monsoonal flow and, most important, 
no AEJ. In other words, the role of orography in controlling the AEJ is at least as important as the role of combined vegetation and evaporation gradients. This is another aspect of Cook's (1999) conclusion that needs to be revisited: in that study the orography was considered flat.

In Figure 10, similarly for what was done in Figure ??, the 600 zonal wind and the corresponding meridional vertical sections at $0^{\circ}$ longitude, together with the meridional horizontal shear induced by the zonal wind, are shown to emphasize the areas that are more 'active' from the point of view of barotropic instability in the various experiments. It is important to realize that the areas with stronger cyclonic vorticity are not necessarily controlled by the stronger AEJ, being also partly controlled by the monsoonal flow. Cyclonic vorticity occurs on the southern side of an easterly jet but also on the northern side of a westerly flow: in both cases barotropic instability can develop. The Experiments seem to suggest that what the AEJ controls is not so much the occurrence of instability, but the confinement of it. For example, Experiment 4, which is remarkable for the absence of an AEJ, does have a broad area of cyclonic shear, mostly induced by the strengthened monsoonal flow, and confined more to the north and to the east of the Control. On the other hand the experiment with uniform $\beta$ imposed to Saharan values shows almost no area over northern Africa where cyclonic vorticity dominates, confirming the overall absence of precipitation noted in Figure 5.

The changes in lower midtropospheric circulation associated with the Experiments are summarized in Fig. 11, by comparing the Control and Experiments geopotential and wind at $600 \mathrm{hPa}$ and $925 \mathrm{hPa}$. The suppression of a strong east- 
erly flow at about $15^{\circ} \mathrm{N}$ in the Experiment 4 is remarkable. $600 \mathrm{hPa}$ wind speed at $15^{\circ} \mathrm{N}$ decreases from about $10 \mathrm{~m} \mathrm{~s}^{-1}$ in the Control to few $\mathrm{m} \mathrm{s}^{-1}$ in the Experiment. This is consistent with the observed change in surface temperature, and the strong weakening of meridional surface temperature gradients which occur in Experiment 4 with respect to the control. Moreover, the southward penetration of the predominantly low-level northerly flow from the eastern Mediterranean feeding into the northern branch of the Hadley cell over Africa, is slightly reduced in the Experiment 4, in which both vegetation properties and evaporation are controlled.

In contrast, the orography experiment allows the flow from the Mediterranean to directly collide with the monsoonal flow, essentially advecting dry air into the ITCZ, consistent with the drastic reduction in precipitation and latent heat shown in Figs. 6 and 7.

Being that the AEJ constrained by the thermal wind relationship, the reciprocal position of surface temperature gradients and zonal winds are emphasized in Fig. 12 for the Control and Experiments 3 and 5, which displays meridional surface temperature gradients against $600 \mathrm{hPa}$ zonal wind. Experiments 3 and 5 are chosen as the two most extreme cases of meridional displacement of surface temperature gradients: in Experiment 3 the maximum gradient is displaced as far north as $20^{\circ} \mathrm{N}$, whereas in Experiment 5 is displaced southward over western Africa, and almost to the Equator over Eastern Africa. While in Experiment 3 a feature resembling the AEJ can be identified in good correspondence to the maximum temperature surface gradient, Experiment 5 shows that basically the 
AEJ disappears merging within the predominatly easterly flow associated with the ITCZ. This impressive change emphasizes the importance of orography in creating meridional surface temperature gradients.

The overall findings indicate that the AEJ is a very fragile element of the Tropical Meteorology, strongly constrained by boundary forcings, and that variations in these constrains may lead to a completely different atmospheric regime.

\section{Discussion and dynamical implications}

This work starts with an analysis of the AEJ using the ERA-40 data and comparing the AEJ representation with that in other state-of-the-art reanalysis data sets, namely the JRA-25 and the NCEP R2. Despite some agreement among these representations, and despite some consistency with pre-existing data sets regarding the definition of the AEJ, it is found that some degree of ambiguity in terms of AEJ shape and intensity still persists, indicating the need for a denser observational coverage over the Sahelian region.

A Control simulation and a set of five experiments are then performed using the NSIPP-1 Atmospheric General Circulation Model. The Control is designed to be a realistic representation of the atmosphere in which, among other forcings, realistic land-surface properties, realistic orography and realistic SSTs are adopted. The model has previously been demonstrated to satisfactorily reproduce climate variability (Schubert et al. 2000; Giannini et al. 2003). The Control run produces a reasonable circulation over Africa and represents well the AEJ. The five experiments are designed to test the roles of various forcings, namely vegetation type, 
soil moisture gradients (with two settings), vegetation type and soil moisture gradients combined together, and orography. A sophisticated treatment of vegetation is used, that determines a whole set of land surface properties including, but not limited to, albedo.

The most important result is that the meridional thermal gradients associated with the AEJ are primarily controlled by gradients of continental surface properties. In a GCM experiment in which both the evaporability and vegetation of the land surface are prescribed to uniform, moderate values (i.e., those obtained in a Control climate run over the Sahel region) over the entire African continent, a general circulation is produced that completely suppresses the AEJ. Interestingly, experiments in which vegetation and evaporability are prescribed separately both result in a distinct AEJ, albeit one of somewhat different strength and position. This result contrasts with the idealized experiments of Cook (1999) in which soil moisture gradients alone controlled the AEJ. Indeed, a similar effect occurs in our model when the soil moisture gradients are eliminated in an extreme experiment in which we effectively set the evaporability to zero (i.e., to Saharan values) over the entire continent. However, this experiment not only eliminates the AEJ but also the African ITCZ and results in a very unrealistic general circulation over the entire African monsoon region.

Among the various changes noted in the general circulation produced by Experiment 4, in which both vegetation and evaporation are controlled, we emphasize: a) the weakening of the Harmattan flow, b) the corresponding strengthening of the monsoonal flow and c) the overall increased zonality of the circu- 
lation over Northern Africa. These changes are consistent with the Reale and Dirmeyer (2002) findings on the effects of suppressing the interannual variability of $\beta$. Those experiments were performed with the same methodology as in KA00, but globally and on a different model. The Reale and Dirmeyer (2002) study, based on a single realization, found a mid-tropospheric negative vorticity anomaly over the Sahelian region suggestive of a northward shift of the ITCZ and a weakening of the AEJ as a consequence of disabling globally the interannual variability of $\beta$.

From this perspective, the results from this study, which are obtained with a more localized change (only Africa) and with a 3-member ensemble, are much more robust and support the idea that a combination of meridional gradients of soil moisture and vegetation properties (including albedo) are crucial for maintaining the AEJ.

The topography experiment (Experiment 5) is also relevant. Suppressing the topography, of which a prominent feature are the Ethiopian Highlands, well represented in the model's resolution (Fig. 4), leads to a strong increase in temperature over East and equatorial Africa and a dramatic reduction of precipitation in the eastern side of the African ITCZ. These two factors act in the same direction of Experiment 4: namely the disappearance of meridional positive surface temperature gradients at about $10^{\circ}-15^{\circ} N$ (Fig. 8). In other words, the combination of vegetation properties and soil moisture gradients produces the same effects of orography, particularly over eastern Africa.

Since the Control experiment includes all of these forcings (varying vegeta- 
tion, varying evaporability and realistic topography), and since the suppression of the first two leads to the disappearance of the AEJ as does the suppression of the third, it can be safely argued that orography is just as important a player in the maintenance of the AEJ, as the vegetation and evaporability. This finding was not accessible to previous experiments that used more idealized simulations with unrealistic orography.

Finally, another important aspect is the nonlinearity of the response to the combined action of prescribing $\beta$ and vegetation properties together. The prescription of uniform Sahelian values of $\beta$ over the entire continent has an effect on temperature gradients that is opposite in sign to that of imposing uniform vegetation. However, when both forcings are prescribed together in Experiment 4, their effects do not appear additive. This is further clarified in Fig. 13 where surface latent heat flux, temperature and precipitation anomalies (computed as Experiment minus Control) are displayed together for Experiments 1, 3, 4 and compared with the simple sum of the anomalies computed from Experiments 1 and 3 . When constant $\beta$ and constant vegetation act together in Experiment 4, their net result is very different from the simple addition of the individual anomalies.

\section{Conclusions}

This work investigates the African Easterly Jet within the framework of a realistic global model simulation. The current understanding of the AEJ is discussed with the aid of reanalyses data sets, and five experiments are designed to assess the importance of vegetation, soil moisture gradients and orography for forming 
and maintaining the Jet. The results further strengthen the original intuition at the basis of the Charney feedback (Charney et al. 1977) by confirming the sensitivity to vegetation change of the Sahel. In particular, decrease in vegetation (corresponding in part to a increase in albedo) over the Sahel leads to an altered surface radiation balance which in turn leads to decreased evaporation and decreased precipitation.

However, the increased realism of vegetation modeling, which now includes many other properties besides albedo, and the more sophisticated treatment of evaporation introduce new insights and add substantial complexity to the problem. Several steps have been taken in this direction by various authors. In particular, in the process of further refining our understanding of the African meteorology, this work aims to continue the research performed by Cook (1999).

Because of the use of a more realistic model with higher vertical and horizontal resolution, and the use of multiple realization ensemble runs, this study provides a more robust assessment of the mechanisms contributing to the AEJ. The results presented here confirm that soil moisture is indeed an important forcing, thus partly agreeing with previous findings by Cook (1999). However, the set of experiments performed also suggest that not only evaporation gradients, but a combination of vegetation properties and orography are also essential for the maintenance of the mean climatological AEJ. In other words, according to this study, it is the very particular combination of moisture gradients, vegetation distribution and orography that produces the AEJ, not the soil moisture gradients alone. 
Finally, this work emphasizes the fragility of the African Easterly Jet, which appears as a somewhat fortuitous element of tropical African meteorology, subject to fluctuations or even disappearance whenever one of the boundary forcings is altered. In particular, there are several studies documenting the possible impact of deforestation on regional climate: among these, changes in precipitation and squall systems propagation on the Amazon (Da Silva et al., 2008); global changes affecting Europe Asia and the United States (Findell et al. 2007) and even teleconnections arising out of possible future deforestation over the Amazon and central Africa (Avissar and Werth 2005). Most relevant is the study by Taylor et al. (2002) which investigated the impact of land surface change on Sahelian climate, demonstrating its sensitivity to small changes in albedo and leaf area index. It is therefore likely that change in vegetation over the Sahel may impact precipitation, soil moisture gradients and consequently even the AEJ.

This aspect has some socio-economic implications, suggesting that land-surface use over the Sahelian region should be carefully considered and that large-scale dramatic changes in terms of deforestation and clearings to the south of the Jet, over Equatorial Africa, may have repercussions on regional and larger-scale climate.

Acknowledgments This work was supported by the NASA Earth Science Enterprise's Global Modeling and Analysis Program. 


\section{REFERENCES}

Arakawa, A., and M. J. Suarez, 1983: Vertical differencing of the primitive equations in sigma coordinates. Mon. Wea. Rev., 111, 34-45.

Asnani, G. C., 2005: Tropical Meteorology. Publisher: Indian Institute of Tropical Meteorology, Pashan, Pune-411008, India. 3 vols.

Avissar, R., and D. Werth, 2005: Global Hydroclimatological Teleconnections Resulting from Tropical Deforestation. J. Climate, 6, 134-145.

Bacmeister, J. T., P. J. Pegion, S. D. Schubert, and M. J. Suarez, 2000: Atlas of seasonal means simulated by the NSIPP-1 atmospheric GCM. NASA Goddard Space Flight Center, NASA Tech. Memo 104606, Vol. 17, 194pp.

-, and M. J. Suarez, 2002: Wind stress simulations and the equatorial momentum budget in an AGCM. J. Atmos. Sci, 59, 3051-3073.

Burpee, R. W., 1972: The origin and structure of easterly waves in the lower troposphere of north Africa. J. Atmos. Sci, 29, 77-90.

Charney, J., W. J. Quirk, S.-h. Chow, and J. Kornfield, 1977: A comparative study of the effects of albedo change on drought in semi-arid regions. . $J$. Atmos. Sci., 34, 1366-1385.

Chen, T.-C., and H. van Loon, 1987: Interannual variation of the Tropical Easterly Jet. Mon. Wea. Rev., 115, 1739-1759.

Chen, T. H., and Coauthors, 1997: Cabauw experimental results from the Project for Intercomparison of Land-Surface Parameterization Schemes. J. Climate, 10, 11941215.. 
Chou, M.-D., and M. J. Suarez, 1994: An efficient thermal infrared radiation parametrization for use in general circulation models. NASA Goddard Space Flight Center, NASA Tech. Memo 104606, Vol 3, 85 pp.

-, and -, 1999: A solar radiation parametrization for use in general circulation models. NASA Goddard Space Flight Center, NASA Tech. Memo 104606, Vol 11, 40 pp.

Clark, D. B., C. M. Taylor, and A. J. Thorpe, 2004: Feedback between the Land Surface and rainfall at convective lenght scales. J. Hydrometeor., 5, 625-639.

Cook, K., 1999: Generation of the African Easterly Jet and Its Role in Determining West African Precipitation. J. Climate, 14, 1165-1184.

- , and E. K. Vizy, 2006: Coupled model simulations of the West African Monsoon System: twentieth- and twenty-first-century simulations. $J . C l i-$ mate, 19, 3861-3703.

Da Silva, R. R., D. Werth, and R. Avissar, 2008: Regional Impacts of Future Land-Cover Changes on the Amazon Basin Wet-Season Climate, J. Climate, 21, 11531170.

Dhonneur, G. 1971: General circulation and types of weather over western and central Africa. Annex IV, GATE Design, JOC, WMO, 22pp.

Douville, H., F. Chauvine, and H. Broqua, 2005: Influence of soil moisture on the Asian and African Monsoons. Part I: Mean Monsoon and daily precipitation. J. Climate, 14, 2381-2403. 
Giannini, A., R. Saravanan, and P. Chang, 2003: Oceanic forcing of Sahel rainfall on interannual to interdecadal time scales. Science, 302, 10271030. DOI: $10.1126 /$ science. 1089357.

Findell, K. L., E. Shevliakova, P. C. D. Milly, and R. J. Stouffer, 2007: Modeled Impact of Anthropogenic Land Cover Change on Climate. J. Climate, 20, 3621-3634.

Foland, C. K., Palmer, T. N., Parker, D. E. 1986: Sahel rainfall and worldwide sea temperatures. Nature, 320, 602-607.

Gibson, J.K., P. Kallberg, S. Uppala, A. Hernandez, A. Nomura and E. Serrano, 1997: ERA Description. ECMWF Re-Analysis Project Report Series, 1.

Hall N. M. J., G. N. Kiladis, and C. D. Thorncroft, 2006: Three-Dimensional Sturcture and Cynamics of African Easterly Waves. Part II:Dynamical Modes, J. Atmos. Sci., 63, 2231-2245.

Hamilton, R. A., and J. W. Archibold, 1945: Meteorology of Nigeria and adiacent territories. Q. J. Roy. Met. Soc., 71, 231-264.

Hagos, S. M., and K. Cook, 2005: Influence of surface processes over Africa on the Atlantic Marine ITCZ and South American Precipitation. J. Climate, 18, 4993-5010.

Houze, R. A., Jr., 1977: Structure and dynamics of a tropical squall-line system observed during GATE. Mon. Wea. Rev., 105, 1540-1567.

Hsieh, J.-S., and K. Cook, 2005: Generation of African Easterly Wave distur- 
bances: Relationship to the African Easterly Jet. Mon. Wea. Rev. 133, 1311-1327.

—, and —, 2007: A study of the energetics of African Easterly Waves usign a regional climate model. J. Atmos. Sci. 64, 421-440.

—, and -, 2008: On the instability of the African Easterly Jet and the generation of African Waves: reversal of the potential vorticity gradient. $J$. Atmos. Sci. 65, 2130-2151.

Kallberg, P., A. Simmons, S. Uppala, and M. Fuentes, 2004: The ERA-40 archive. ERA-40 Project Report Series, 17, 1-31. Available online at http://www.ecmwf.int/publications/library/do/references/list/192

Kanamitsu M., W. Ebisuzaki, J. Woollen, S.-K. Yang, J. J. Hnilo, M. Fiorino, and G. L. Potter, 2002: NCEPDOE AMIP-II Reanalysis (R-2). Bull. Amer. Meteor. Soc., 83, 16311643.

Kiladis, G. N., C. D. Thorncroft, and N. M. J. Hall, 2006: Three-Dimensional Sturcture and Cynamics of African Easterly Waves. Part I:Observations, J. Atmos. Sci., 63, 2212-2230.

Kistler, R., E. Kalnay, W. Collins, S. Saha, G. White, J. Woollen, M. Chelliah, W. Ebisuzaki, M. Kanamitsu, V. Kousky, H. van den Dool, R. Jenne, and M. Fiorino, 2001: The NCEP-NCAR 50-year reanalysis: Monthly means CD-ROM and documentation. Bull. Amer. Meteor. Soc., 82, 247-267.

Koster, R. D., and M. J. Suarez, 1992: Modeling the land surface boundary in climate models as a composite of independent vegetation stands. $J$. 
Geophys. Res., 97, 26972715.

—, and -, 1995: Relative contributions of land and ocean processes to precipitation variability. J. Geoph. Res., 100, 13,775-13,790.

-, and -, 1996: Energy and water balance calculations in the Mosaic LSM. NASA Goddard Space Flight Center, NASA Tech. Memo. 104606, Vol. 9., $59 \mathrm{pp}$.

-, 一, and M. Heiser, 2000: Variance and Predictability of Precipitation at Seasonal-to-Interannual Timescales. J. Hydrometeor., 1, 26-46.

Louis, J., M. Tiedtke, and J. Geleyn, 1982: A short history of the PBL parametrization at ECMWF. Proc. ECMWF Workshop on Planetary Boundary Layer Parametrization, Reading, United Kingdom, ECMWF, 59-80.

Moorthi, S., and M. J. Suarez, 1992: Relaxed Arakawa-Schubert: A parametrization of moist convection for general circulation models. Mon. Wea. Rev., 120, 978-1002.

Nicholson, S. E., 1997: An analysis of the ENSO signal in the Tropical Atlantic and western Indian Ocean. Int. J. Climatology., 17, 345-375.

—, and J. Kim, 1997: The relationship of the ENSO to African Rainfall. Int. J. Climatology., 17, 117-135.

Onogi, K., J. Tsutsui, H. Koide, M. Sakamoto, S. Kobayashi, H. Hatsushika, T. Matsumoto, N. Yamazaki, H. Kamahori, K. Takahashi, S. Kadokura, K. Wada, K. Kato, R. Oyama, T. Ose, N. Mannoji and R. Taira, 2007: The JRA-25 Reanalysis. J. Meteor. Soc. Japan, 85, 369-432. 
Parker, D. J., A. Fink, S. Janicot, J.-B. Ngamini, M. Douglas, E. Afiesimama, A. Agusti-Panared, A. Beljaars, F. Dide, A. Diedhiou, T. Lebel, J. Polcher, J.-L. Redelsperger, C. Thorncroft, and G. Ato Wilson, 2008: The AMMA radiosonde program and its implications for the future of atmospheric monitoring over Africa. Bull. Am. Meteor. Soc., 89, 1015-1027.

Pegion, P. J., Schubert, and M. J. Suarez, 2000: An assessment of the predictability of northern winter seasonal means with the NSIPP 1 AGCM. NASA Goddard Space Flight Center, NASA Tech. Memo 104606, Vol. $18,110 \mathrm{pp}$.

Reale, O., and P. Dirmeyer, 2002: Modeling the effect of land-surface evaporation variability on precipitation variability. Part I: General response. $J$. Hydrometeor., 3, 433-450.

- , 一, and A. Schlosser, 2002: Modeling the effect of land-surface evaporation variability on precipitation variability. Part II: Time- and space-scale structure. J. Hydrometeor., 3, 451-466.

Schubert, S. D., M. J. Suarez, P. J. Pegion, M. A. Kistler, and A. Kumer, 2002: Predictability of zonal means during boreal summer. J. Climate, 15, 420434.

Semazzi, F. H. M., B. Burns, N.-H. Lin, and J.-K. Schemm, 1996: A GCM study of the teleconnections between the continental climate of Africa and Global Sea Surface Temperature anomalies. 2002: Predictability of zonal means during boreal summer. J. Climate, 9, 2480-2497. 
Simmsons, A., and J.K. Gibson, 2000: The ERA-40 project plan. ERA-40 Project Report Series, 1, 1-63. Available online at http://www.ecmwf.int/publications/library/do/references/list/192

Suarez M. J., and L. L. Takacs, 1995: Documentation of the Arries-GEOS dynamical core: version 2. NASA Goddard Space Flight Center, NASA Tech. Memo. 104606, Vol. 5, 45 pp.

Taylor, C. M., E. F. Lambin, N. Stephenne, R. J. Hardling, and R. L. H. Essey, 2002: The Influence of Land Use Change on Climate in the Sahel. $J$. Climate, 15, 36153629.

Tompkins, A. M., C. Cardinali, J.-J. Morcrette, and M. Rodwell, 2005: Influence of aerosol climatology on forecasts of the African Easterly Jet. Geoph. Res. Letter., 32, L10801, doi:10.1029/2004GL022189.

Thorncroft, C. D., and M. Blackburn, 1999: Maintenance of the African easterly jet $Q$. J. Roy. Met. Soc., 125, 763-786.

—, D. J. Parker, R. R. Burton, M. Diop, J. H. Ayers, H. Bariat, S. Devereau, A. Diongue, R. Dumelow, D. R. Kindred, N. M. Price, M. Saloum, C. M. Tayor, and A. M. Tompkins, 2003: The JET 2000 Project. Aircraft observations of the African Easterly Jet and African Easterly Waves. Bull. Am. Meteor. Soc., 84, 337-351.

Redelsperger, J.-L., C. D. Thorncroft, A. Diedhiou, T. Lebel, D. J. Parker, and J. Polcher, 2006: African Monsoon Multidisciplinary Analysis: An international research project and field campaign. Bull. Am. Meteor. Soc., 
87, 1739-1746.

Tucker, C., Dregne, H. D., and W. W. Newcomb, 1999: Expansiopn and contraction of the Sahara desert from 1980 to 1990 . Science, 253, 299-300. DOI: $10.1126 /$ science.253.5017.299.

Uppala, S. M., P. W. Kallberg, A. J. Simmons, U. Andrae, V. D. Bechtold et al., 2005: The ERA-40 re-analysis. Q. J. R. Meteorol. Soc., 131, 2961-3012.

Xue, Y., and J. Shukla, 1993: The Influence of Land Surface Properties on Sahel Climate. Part 1: Desertification J. Climate, 6, 2232-2245.

Wu, C. M.-L., S. Schubert, M. J. Suarez, and P. J. Pegion, 2006: Seasonality and Meridional Propagation of the MJO. J. Climate, 19, 1901-1921.

Wood, E. F., and Coauthors, 1998: The Project for the Intercomparison of Land-Surface Parameterization Schemes (PILPS) phase 2(c) Red-Arkansas River basin experiment. 1: Experiment description and summary intercomparisons. Global Planet. Change, 19, 115-135.

Vizy, E. K, and K. H. Cook, 2001: Mechanisms by which Gulf of Guinea and Eastern North Atlantic Sea Surface Temperature anomalies can influence African rainfall. J. Climate, 14, 795-821.

Zipser, E. J., and C. Gautier, 1978: Mesoscale Events within a GATE tropical depression Mon. Wea. Rev., 106, 789-805.

Zeng, N. and J. D. Neelin, 2000: The role of vegetation-climate interaction and interannual variability in shaping the African Savanna. J. Climate, 13, $2665-2670$. 


\section{List of Tables}

1 The experiment settings are described. The first column shows the role of albedo and vegetation type. The second column shows the role of the evaporation efficiency $\beta$. The third column refers to the orography. . . . . . . . . . . . . . . 41 


\begin{tabular}{|l|l|l|l|}
\hline & Vegetation & Evaporation Efficiency & Orography \\
\hline Control & Varying & Varying & Realistic \\
EXP 1 & Varying & Prescribed (Sahel conditions) & Realistic \\
EXP 2 & Varying & Prescribed (Sahara conditions) & Realistic \\
EXP 3 & Prescribed & Varyiing & Realistic \\
EXP 4 & Prescribed & Prescribed & Realistic \\
EXP 5 & Varying & Varyiing & Prescribed \\
\hline
\end{tabular}

Table 1: The experiment settings are described. The first column shows the role of albedo and vegetation type. The second column shows the role of the evaporation efficiency $\beta$. The third column refers to the orography. 


\section{List of Figures}

1 July zonal wind ( $m s^{-1}$, contours every $1 \mathrm{~ms}^{-1}, 0$ omitted, solid-positive, dashed-negative) climatology (1980-2001) based on ERA-40, NCEP R2, JRA-25 data, and NSIPP-1 AGCM three ensemble runs: $600 \mathrm{hPa}$ (left column) and cross section at $0^{\circ}$ longitude (right column). . . . . . 45

2 July zonal wind ( $m s^{-1}$, contours every $1 \mathrm{~m} \mathrm{~s}^{-1}, 0$ omitted, solid-positive, dashed-negative) climatology (1980-2001) based on ERA-40, NCEP R2, and JRA-25 data, and meridional horizontal shear of the zonal wind at $600 \mathrm{hPa}$ (left column, contours at $+/-2,1.5,1, .5 .1 \times 10^{-6} s^{-1}$ ). Cross section at $0^{\circ}$ longitude (right column). . . . . . . . . . . 46

3 July zonal wind ( $m s^{-1}$, contours every $1 \mathrm{~m} \mathrm{~s}^{-1}, 0$ omitted, solid-positive, dashed-negative) climatology (1980-2001) based on ERA-40, NCEP R2, and JRA-25 data, and $K(y)$ at $600 \mathrm{hPa}$ (left column, contours at +/ $2,1, .5 \times 10^{-11} \mathrm{~m}^{-1} \mathrm{~s}^{-1}$ ). Cross section at $0^{o}$ longitude (right column). . 47

4 Map of predominant vegetation types. The actual vegeatation in the model is much more complex, since up to six vegetation types can be observed within each gridbox, following a 'mosaic' approach (left panel). Map of model topography (right panel). . . . . . . . . . . . 48

5 JAS surface temperature $(K)$ computed for the Control and Experiments 1, 2, 3, 4, 5 (left column, upper color bar). Right column: differences from the control (lower color bar). . . . . . . . . . . . . . . . . 49 
6 JAS precipitation $\left(m m d^{-1}\right)$ computed for the Control and Experiments 1, 2, 3, 4, 5 (left column, upper color bar). Right column: differences from the control (lower color bar). . . . . . . . . . . . . . . . . . 50

7 JAS latent heat fluxes $\left(W^{-2}\right)$ computed for the Control and Experiments $1,2,3,4,5$ (left column, upper color bar). Right column: differences from the control (lower color bar). . . . . . . . . . . . 51

$8 \quad 1980-2001$ meridional surface temperature gradient $\left(K d e g^{-1}\right)$ computed for the Control and Experiments 1, 2, 3, 4, 5 (left column, upper color bar). Zonal vertical cross-sections of meridional temperature gradient $\left(K \mathrm{Keg}^{-1}\right)$ at $12^{\circ} N$ (central column, middle color bar). Meridional vertical cross-sections of temperature $(K)$ at $0^{\circ}$ longitude (right column, lower color bar). . . . . . . . . . . . . 5 5

9 July zonal wind $\left(\mathrm{m} \mathrm{s}^{-1}\right)$ computed for the Control and Experiments 1, 2, 3, 4, 5 (left column). Right column: meridional vertical cross sections of zonal wind at $0^{\circ}$ longitude. . . . . . . . . . . . . 53

10 July zonal wind $\left(\mathrm{m} \mathrm{s}^{-1}\right)$ computed for the Control and Experiments 1, $2,3,4,5$ (left column) and meridional horizontal shear of the zonal wind at $600 \mathrm{hPa}$ (left column, contours at $+/-2,1.5,1, .5 .1 \times 10^{-6} \mathrm{~s}^{-1}$, solidpositive, dashed-negative). Right column: meridional vertical cross sections of the same quantities at $0^{\circ}$ longitude. . . . . . . . . . . 54

11 Geopotential height $(\mathrm{hm})$ and wind $\left(\mathrm{m} \mathrm{s}^{-1}\right)$ at $600 \mathrm{hPa}$ (left column, upper color bar) and $925 \mathrm{hPa}$ (right column, lower color bar) in the Control and Experiment runs. . . . . . . . . . . . . . . 55 
$12600 \mathrm{hPa}$ zonal wind ( $m s^{-1}$, contours every $1 m s^{-1}, 0$ omitted, solidpositive, dashed-negative) in the Control and Experiments 3 and 5, compared with meridional surface temperature gradients (shaded $K d e g^{-1}$.) $\quad 56$

13 Anomalies (computed as the difference Experiment minus Control) of surface latent heat fluxes (first column), surface temperature (second column) and precipitation (third column) for Experiment 1 (first row), Experiment 3 (second row), Experiment 4 (third row). The last row shows the anomaly sums of Experiment 1 plus Experiment 3. . . . . . 57 

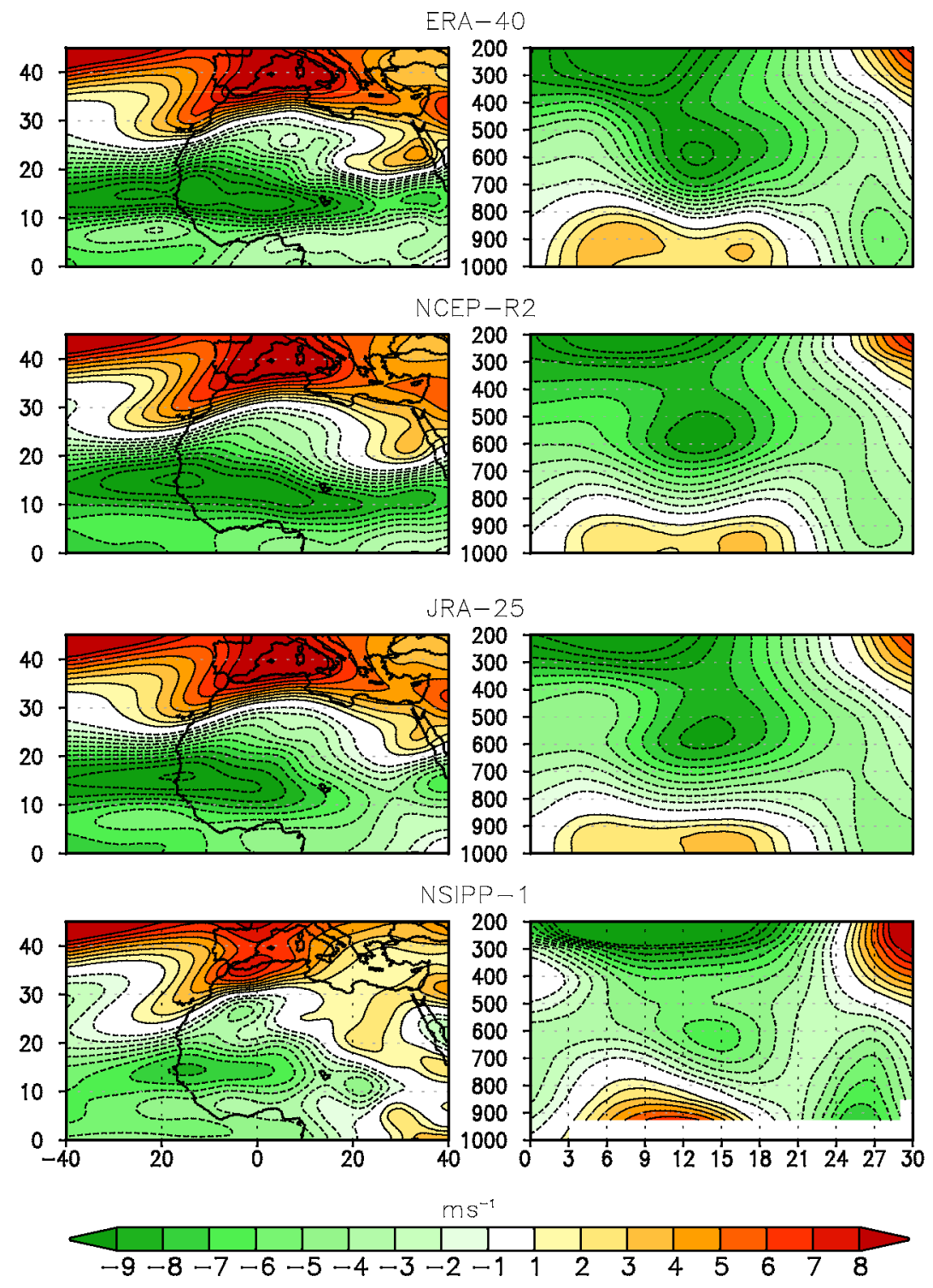

Figure 1: July zonal wind ( $m s^{-1}$, contours every $1 m s^{-1}, 0$ omitted, solid-positive, dashed-negative) climatology (1980-2001) based on ERA-40, NCEP R2, JRA-25 data, and NSIPP-1 AGCM three ensemble runs: $600 \mathrm{hPa}$ (left column) and cross section at $0^{\circ}$ longitude (right column). 

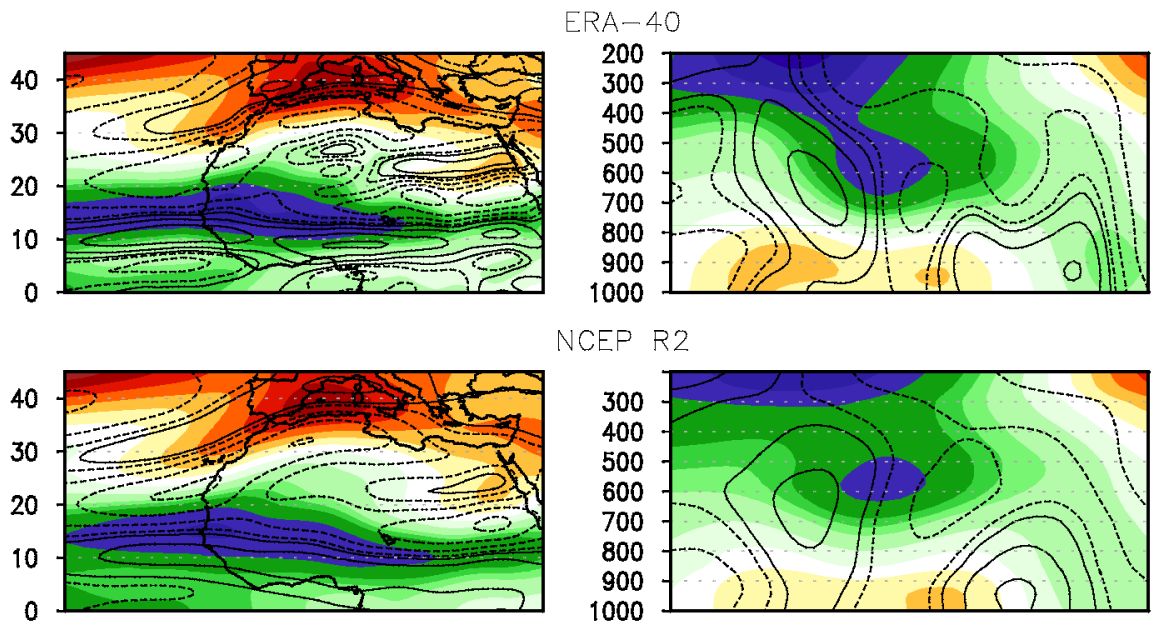

NCEP R2

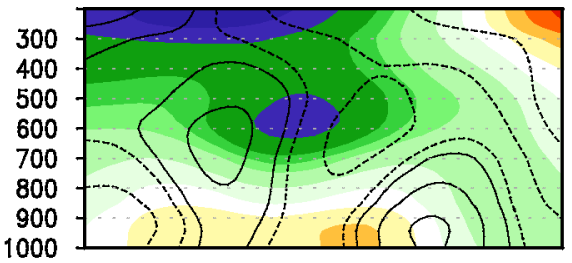

$J R A-25$
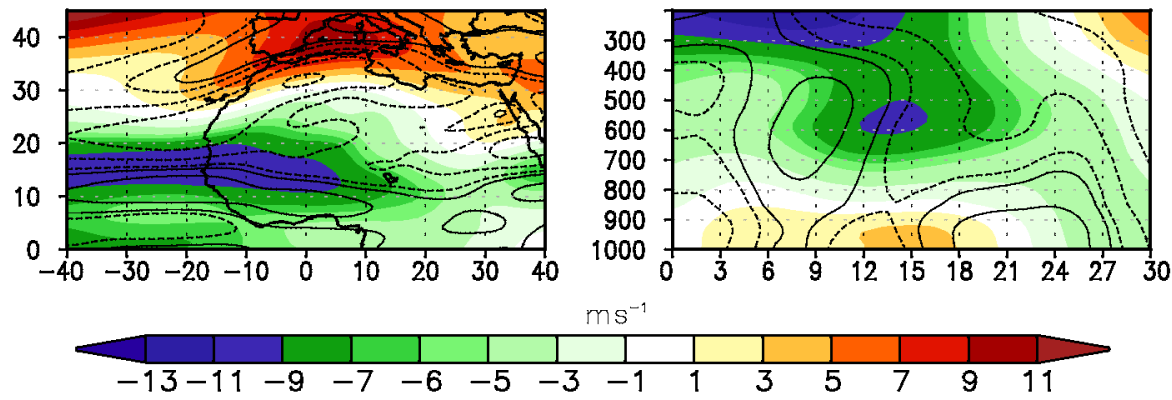

Figure 2: July zonal wind ( $m s^{-1}$, contours every $1 m s^{-1}, 0$ omitted, solid-positive, dashed-negative) climatology (1980-2001) based on ERA-40, NCEP R2, and JRA-25 data, and meridional horizontal shear of the zonal wind at $600 \mathrm{hPa}$ (left column, contours at $+/-2,1.5,1, .5 .1 \times 10^{-6} s^{-1}$ ). Cross section at $0^{\circ}$ longitude (right column). 

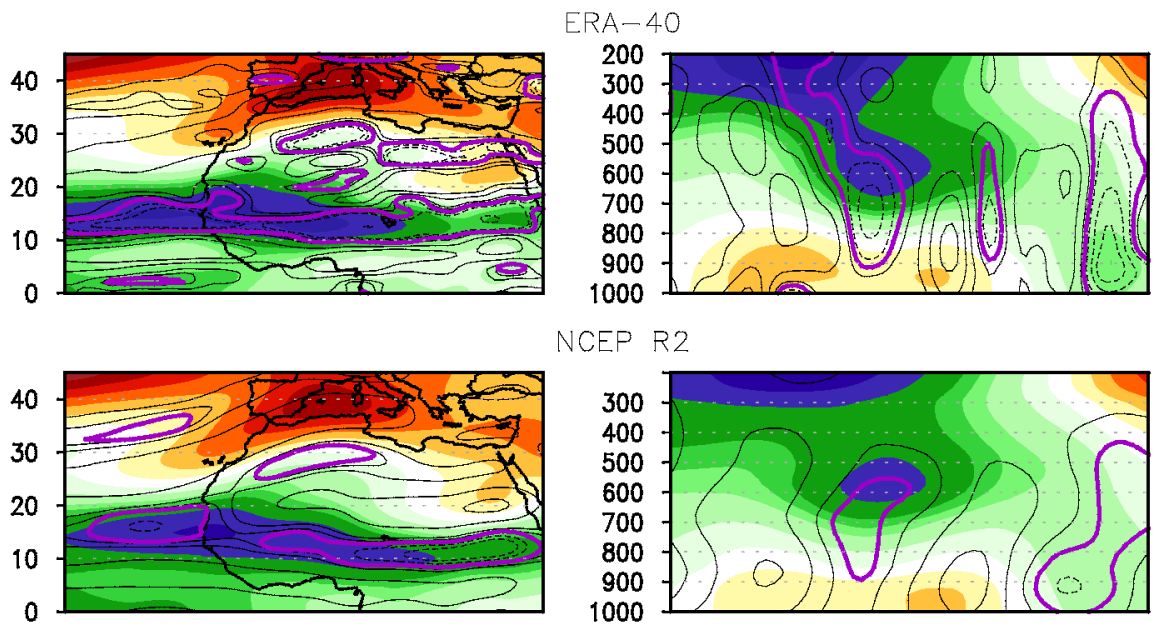

NCEP R2

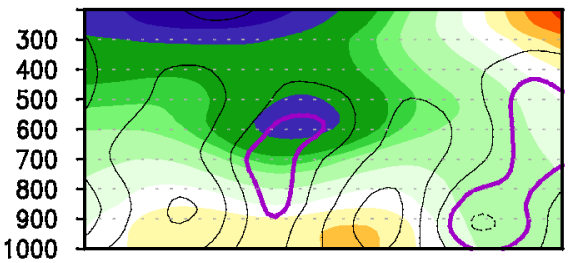

JRA -25
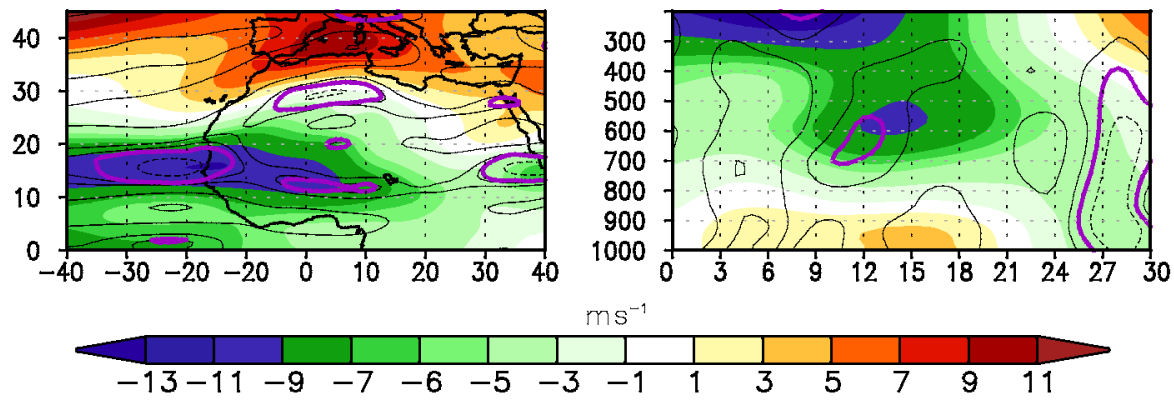

Figure 3: July zonal wind ( $m s^{-1}$, contours every $1 m s^{-1}, 0$ omitted, solid-positive, dashed-negative) climatology (1980-2001) based on ERA-40, NCEP R2, and JRA-25 data, and $K(y)$ at $600 \mathrm{hPa}$ (left column, contours at $+/-2,1, .5 \times 10^{-11} \mathrm{~m}^{-1} \mathrm{~s}^{-1}$ ). Cross section at $0^{\circ}$ longitude (right column). 


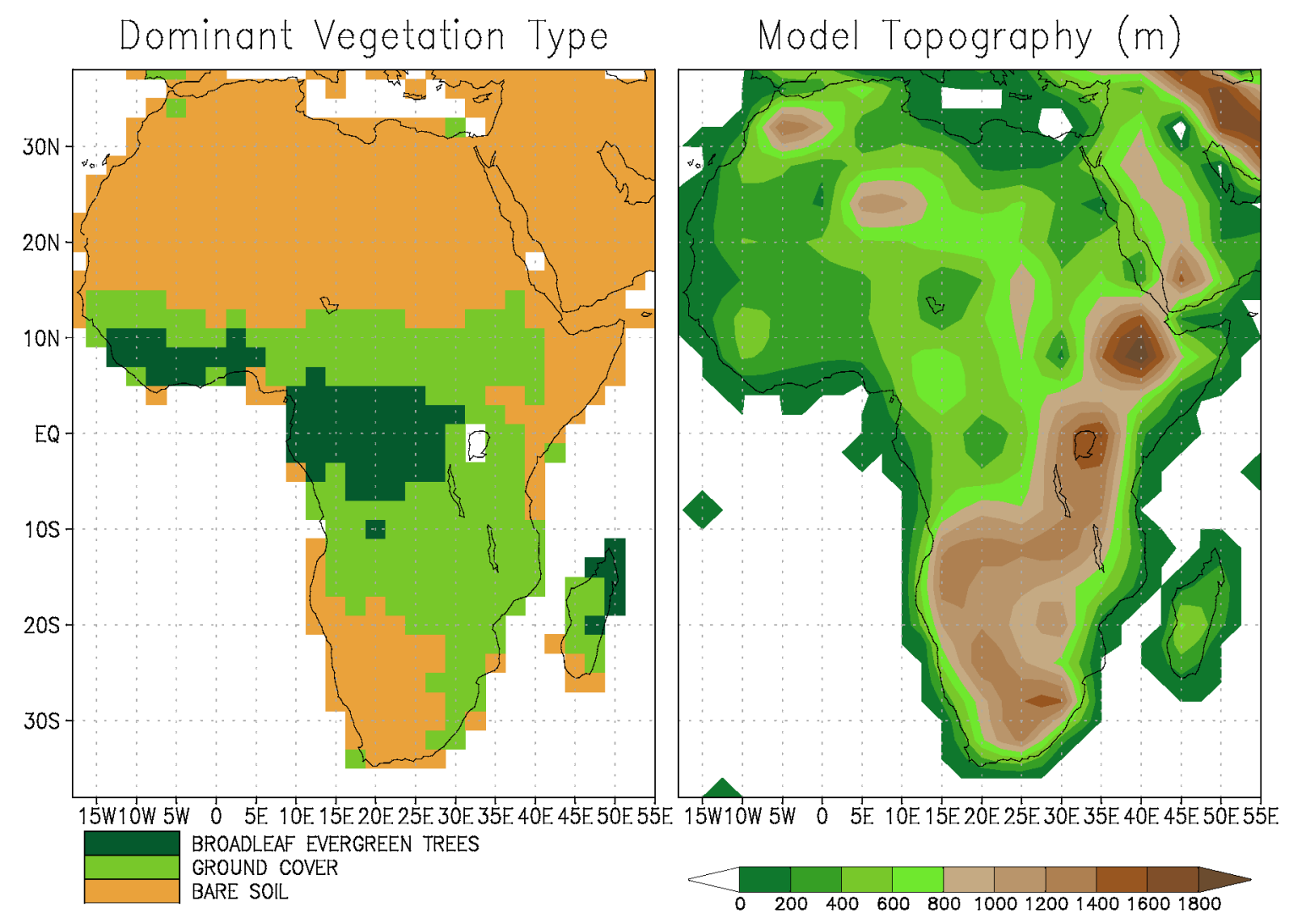

Figure 4: Map of predominant vegetation types. The actual vegeatation in the model is much more complex, since up to six vegetation types can be observed within each gridbox, following a 'mosaic' approach (left panel). Map of model topography (right panel). 


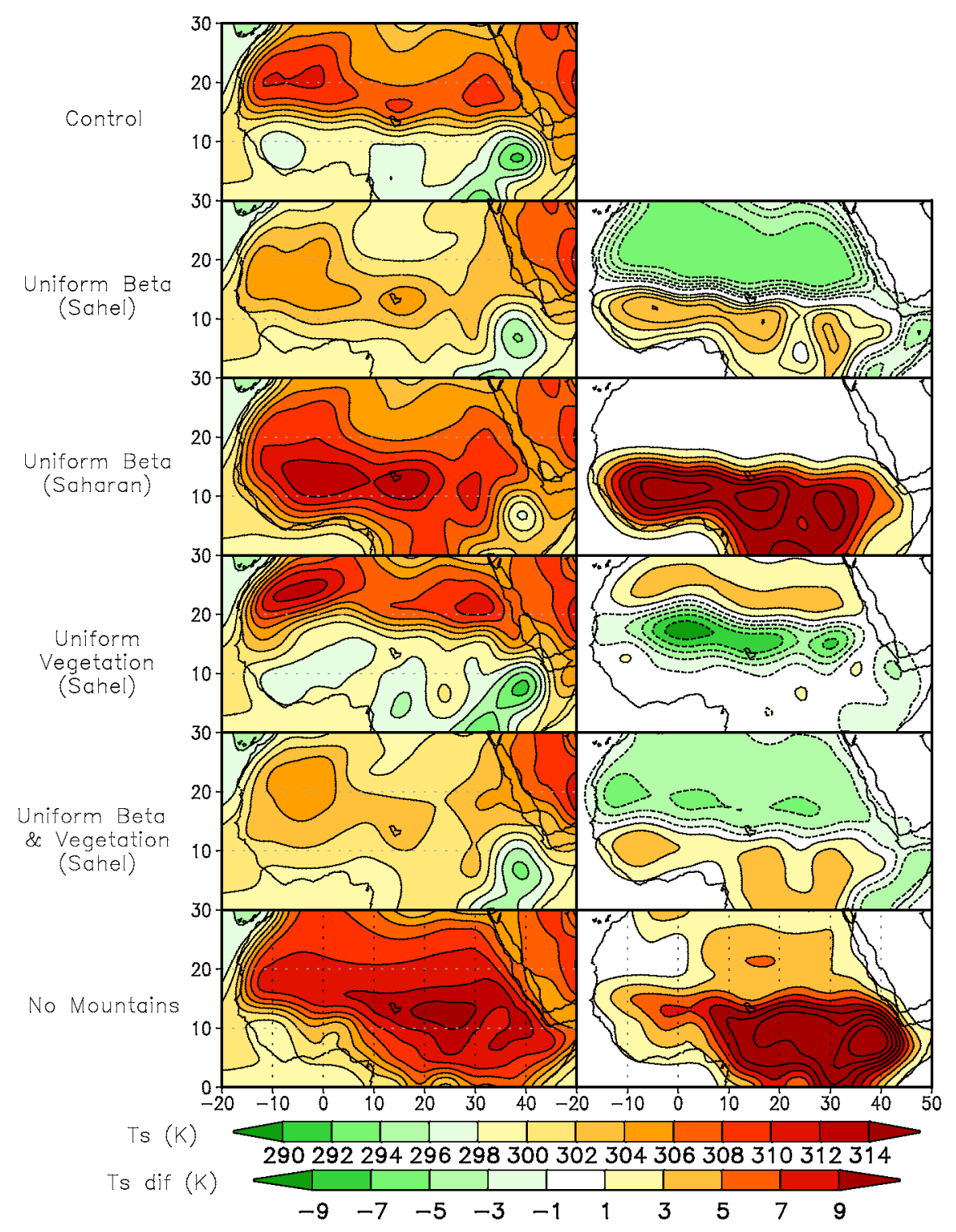

Figure 5: JAS surface temperature $(K)$ computed for the Control and Experiments 1, 2, 3, 4, 5 (left column, upper color bar). Right column: differences from the control (lower color bar). 


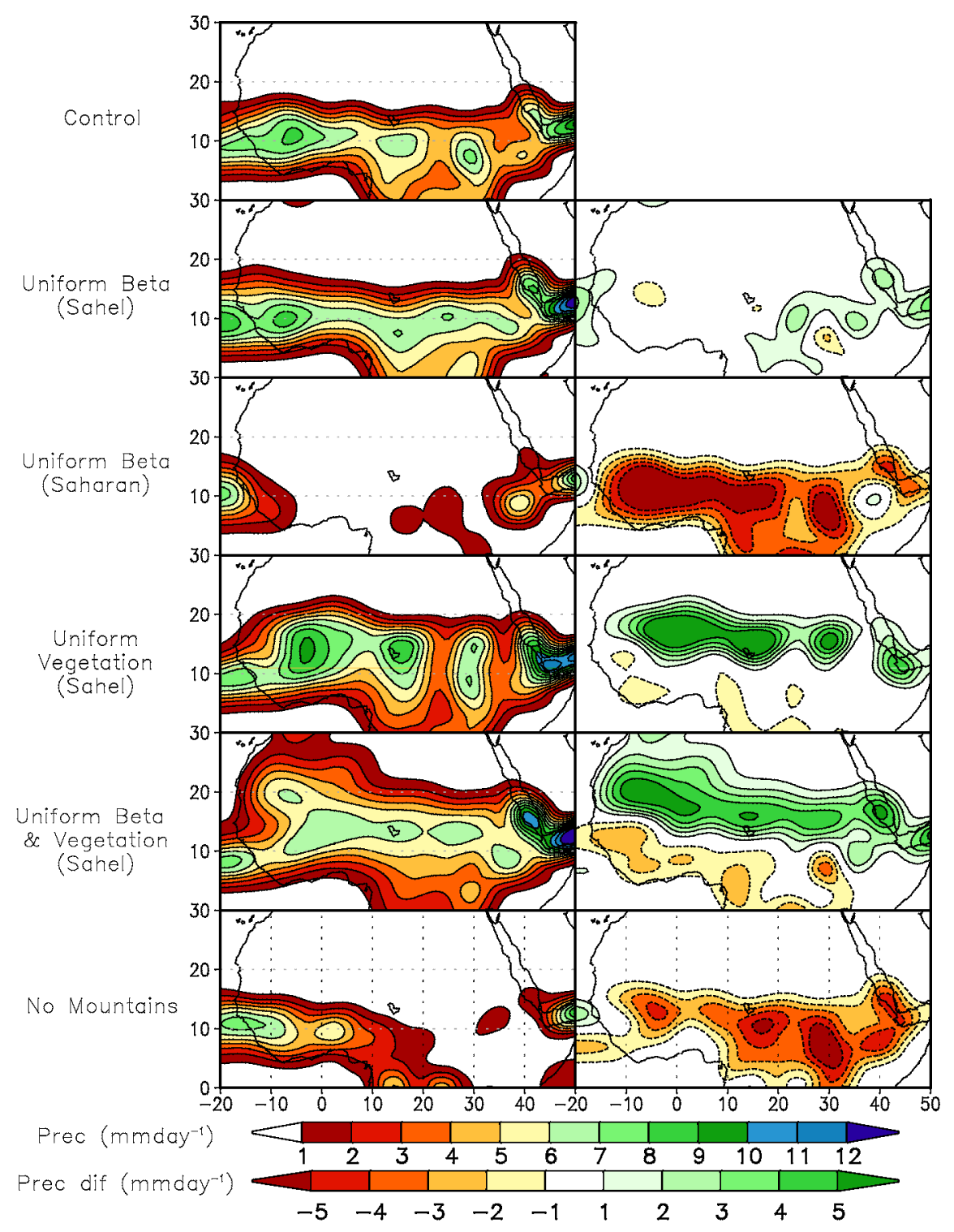

Figure 6: JAS precipitation ( $m m d^{-1}$ ) computed for the Control and Experiments 1, 2, 3, 4, 5 (left column, upper color bar). Right column: differences from the control (lower color bar). 


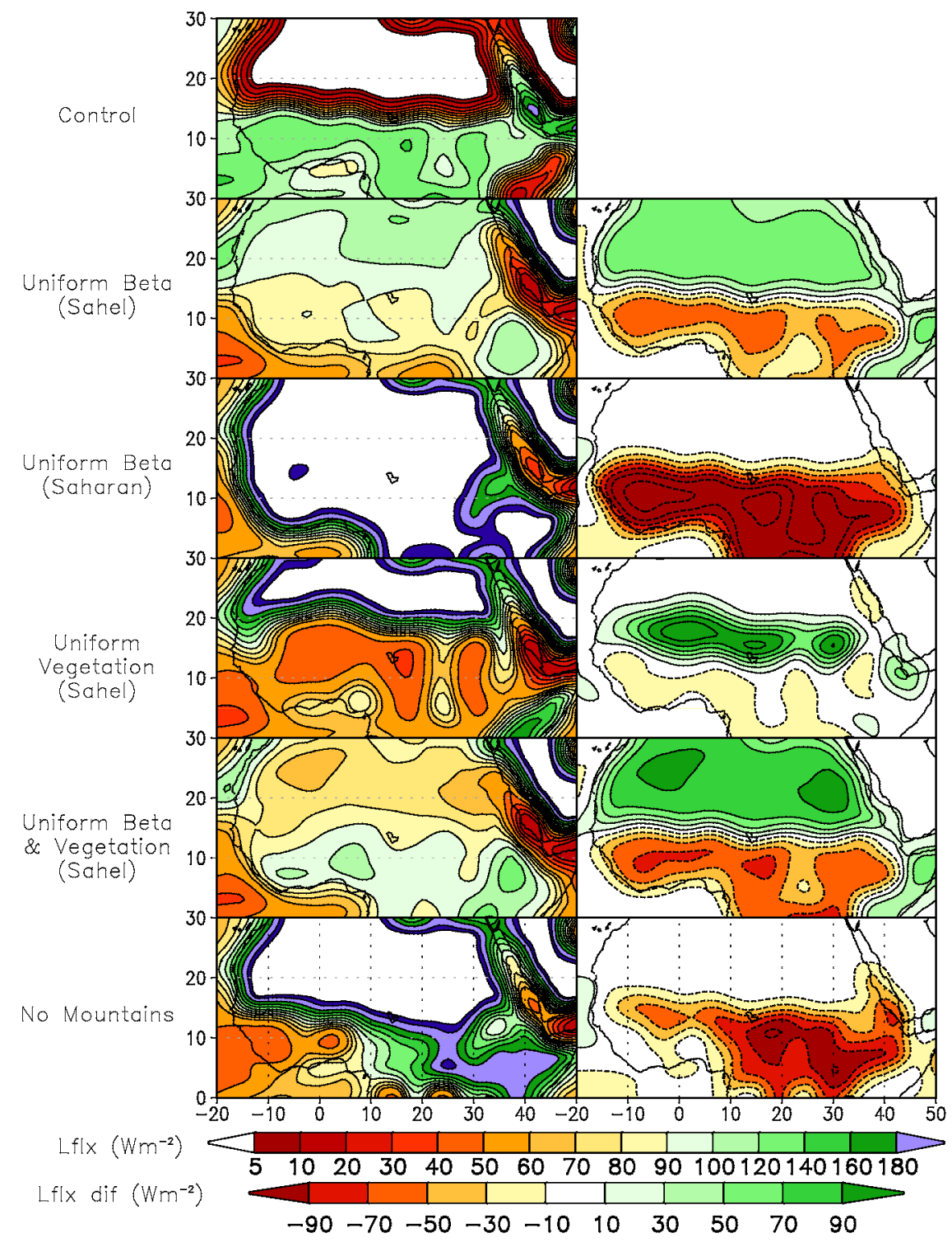

Figure 7: JAS latent heat fluxes $\left(W^{-2}\right)$ computed for the Control and Experiments $1,2,3,4,5$ (left column, upper color bar). Right column: differences from the control (lower color bar). 


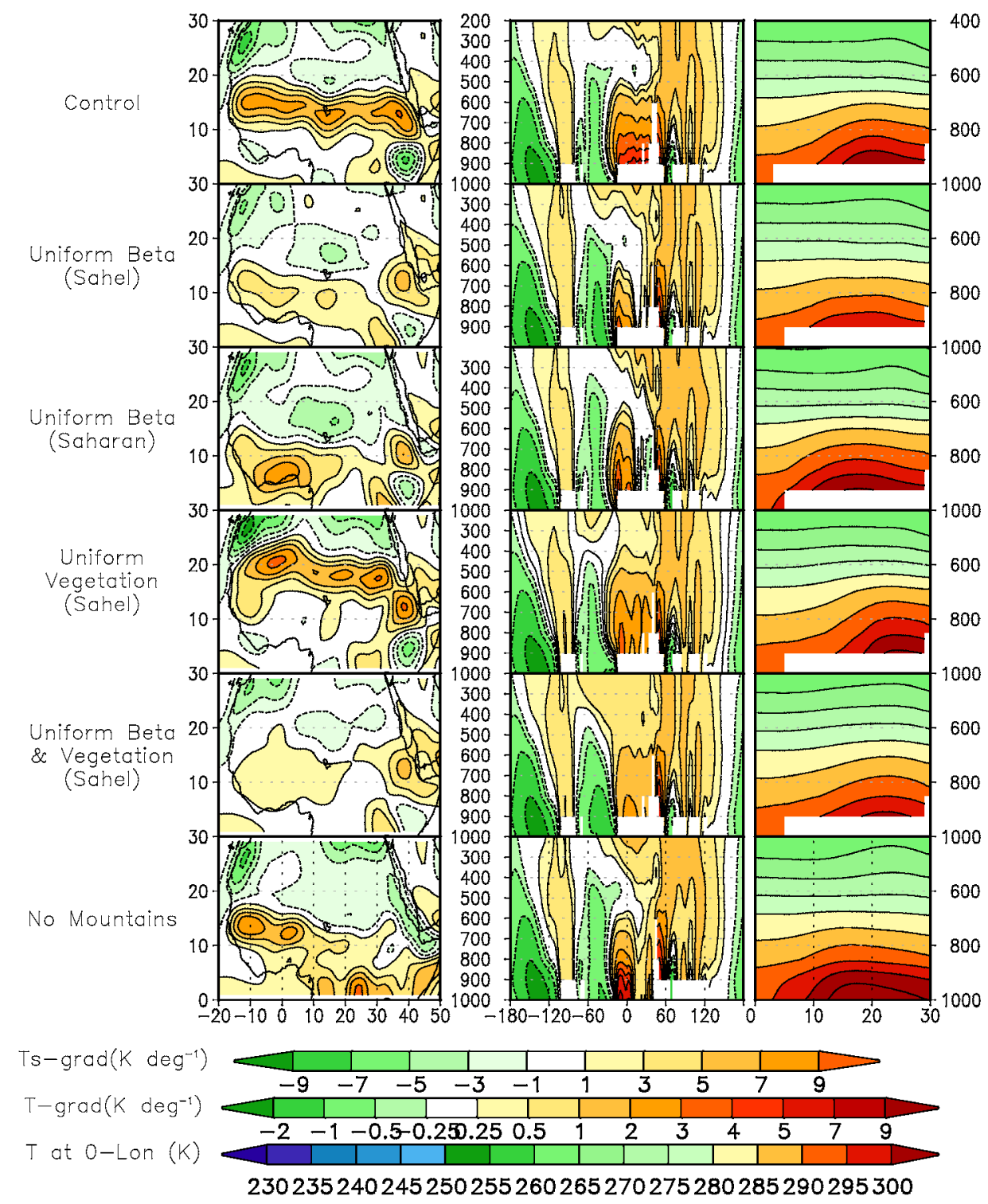

Figure 8: 1980-2001 meridional surface temperature gradient $\left(K \mathrm{deg}^{-1}\right)$ computed for the Control and Experiments 1, 2, 3, 4, 5 (left column, upper color bar). Zonal vertical cross-sections of meridional temperature gradient $\left(K \mathrm{deg}^{-1}\right)$ at $12^{\circ} \mathrm{N}$ (central column, middle color bar). Meridional vertical cross-sections of temperature $(K)$ at $0^{o}$ longitude (right column, lower color bar). 

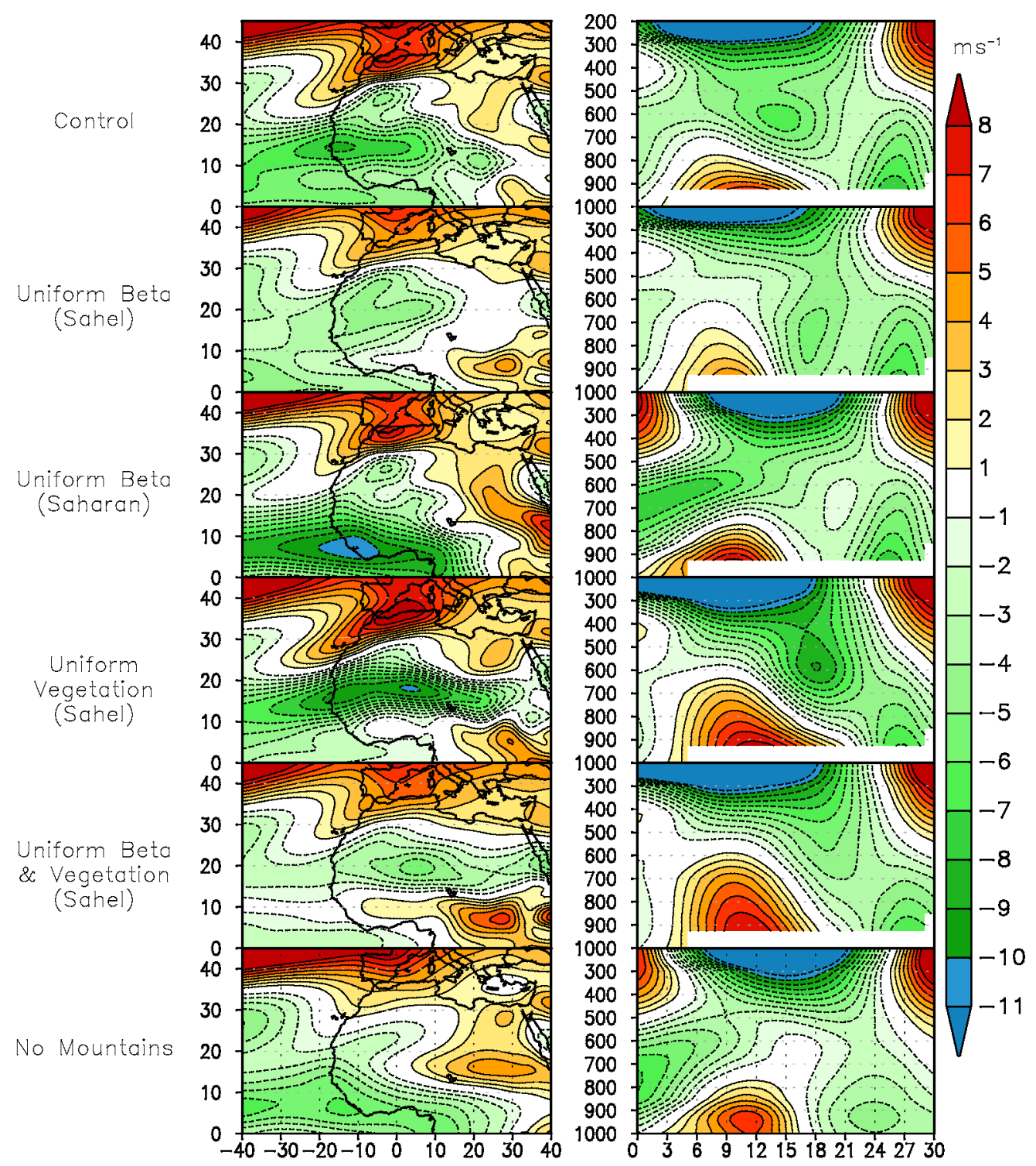

Figure 9: July zonal wind $\left(m s^{-1}\right)$ computed for the Control and Experiments 1, 2, 3, 4, 5 (left column). Right column: meridional vertical cross sections of zonal wind at $0^{\circ}$ longitude. 


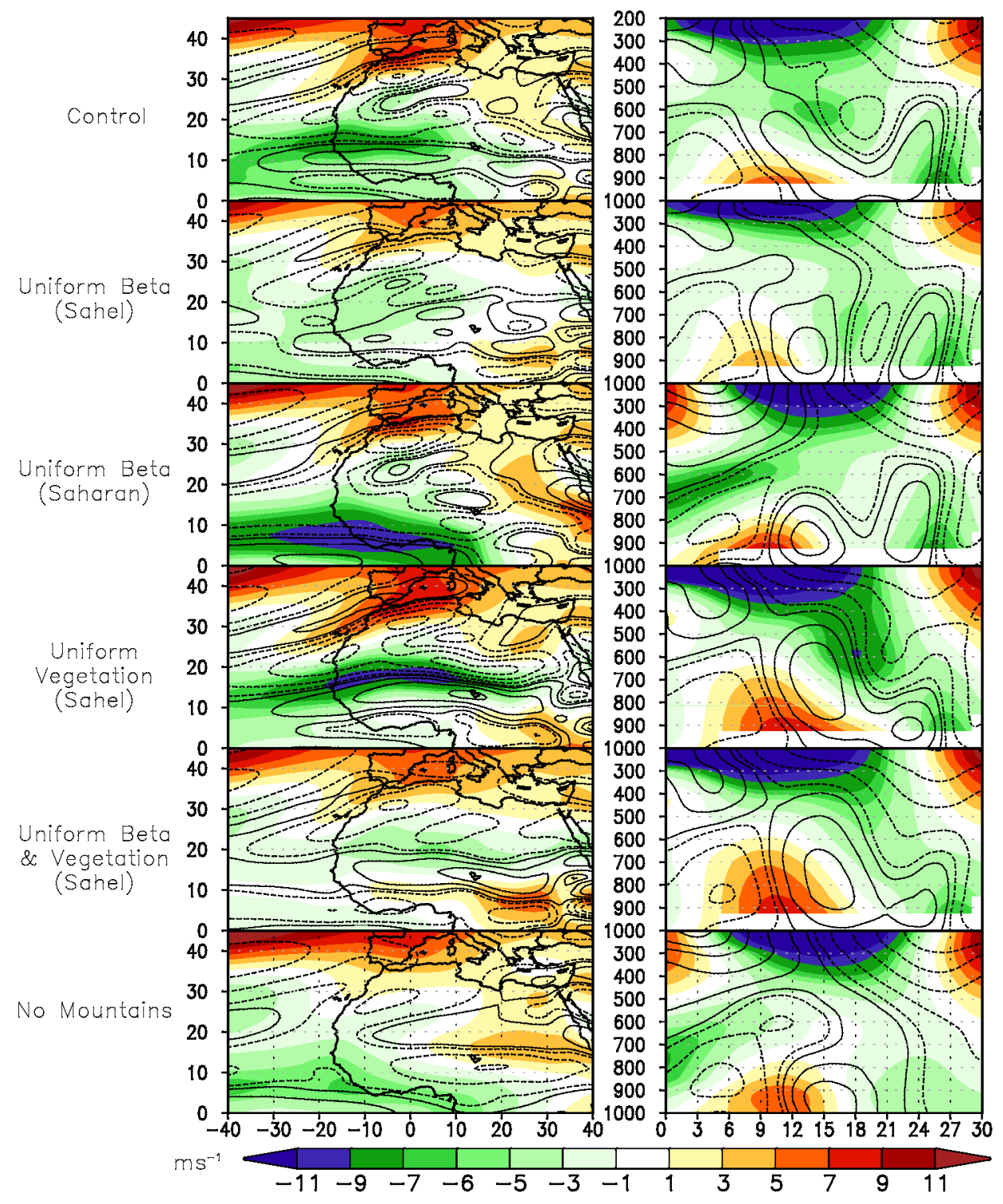

Figure 10: July zonal wind $\left(m s^{-1}\right)$ computed for the Control and Experiments 1, 2, 3, 4, 5 (left column) and meridional horizontal shear of the zonal wind at $600 \mathrm{hPa}$ (left column, contours at $+/-2,1.5,1, .5 .1 \times 10^{-6} s^{-1}$, solid-positive, dashed-negative). Right column: meridional vertical cross sections of the same quantities at $0^{\circ}$ longitude. 


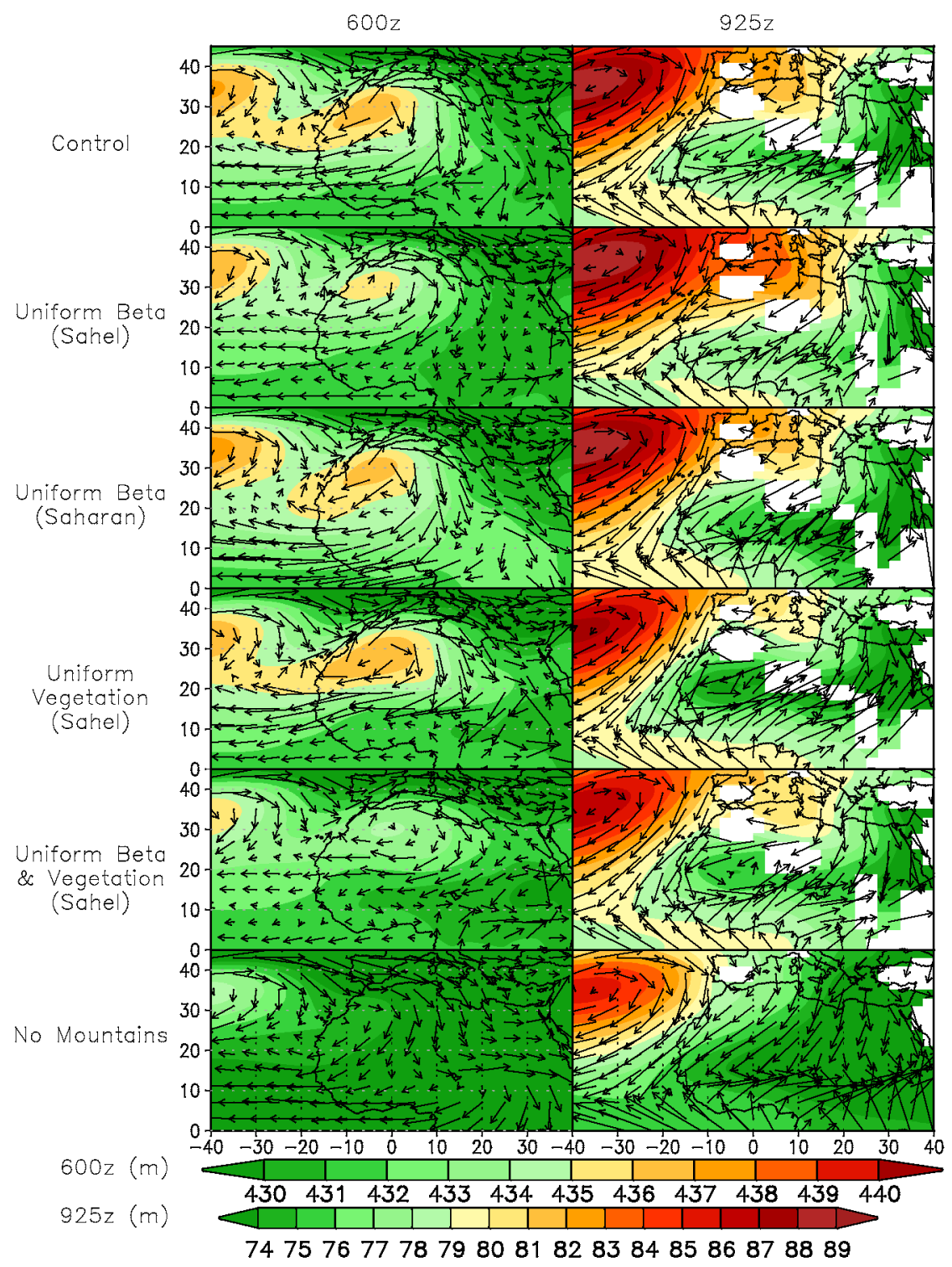

Figure 11: Geopotential height $(\mathrm{hm})$ and wind $\left(\mathrm{m} \mathrm{s}^{-1}\right)$ at $600 \mathrm{hPa}$ (left column, upper color bar) and $925 \mathrm{hPa}$ (right column, lower color bar) in the Control and Experiment runs. 


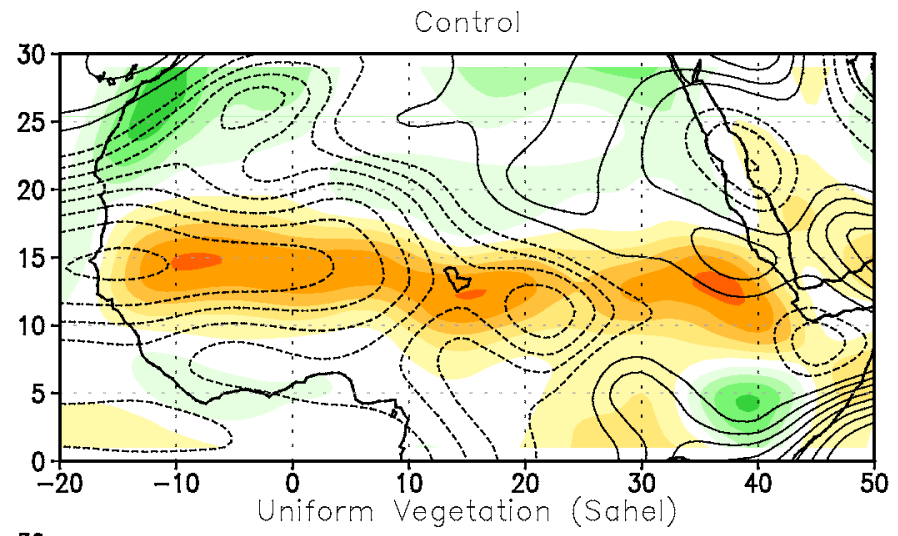

C deg ${ }^{-1}$
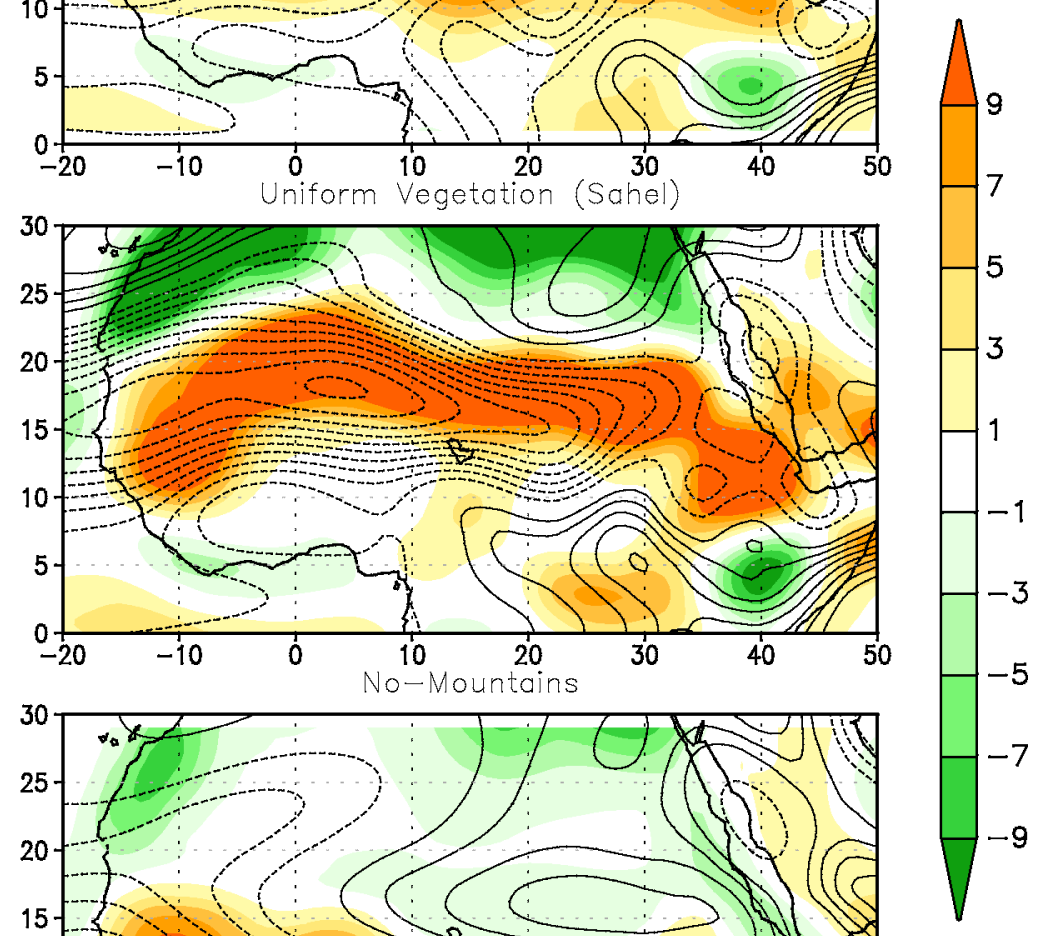

Figure 12: $600 \mathrm{hPa}$ zonal wind $\left(\mathrm{m} \mathrm{s}^{-1}\right.$, contours every $1 \mathrm{~m} \mathrm{~s}^{-1}, 0$ omitted, solid-positive, dashed-negative) in the Control and Experiments 3 and 5, compared with meridional surface temperature gradients (shaded $K \mathrm{deg}^{-1}$.) 


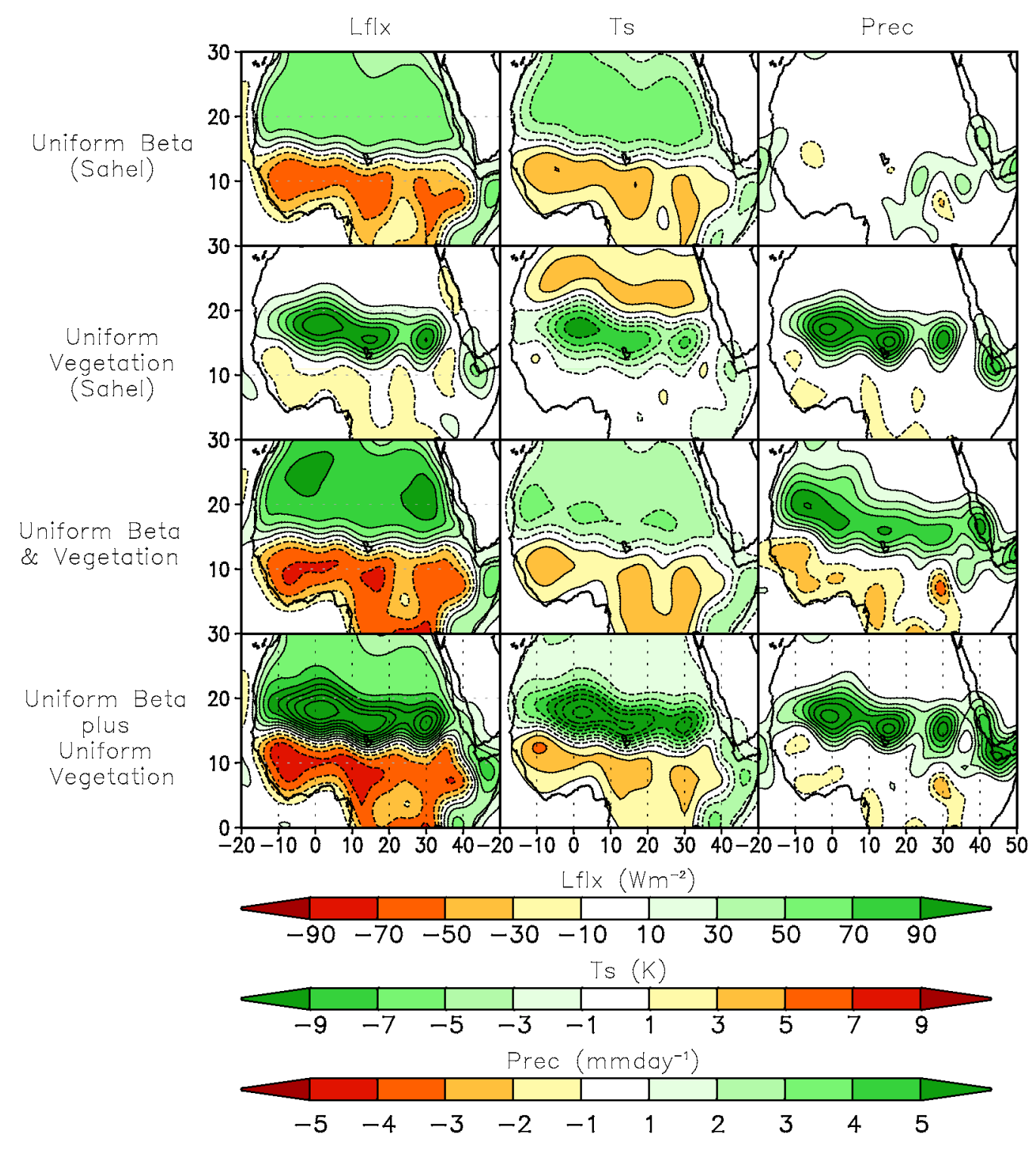

Figure 13: Anomalies (computed as the difference Experiment minus Control) of surface latent heat fluxes (first column), surface temperature (second column) and precipitation (third column) for Experiment 1 (first row), Experiment 3 (second row), Experiment 4 (third row). The last row shows the anomaly sums of Experiment 1 plus Experiment 3. 